\title{
An optimized gene transfection system in WERI-Rb1 cells
}

\author{
YING LIU ${ }^{1}$, ZHIGANG FAN ${ }^{1}, \mathrm{KANG} \mathrm{LI}^{1}$, FEI DENG ${ }^{1}$, YUNFAN XIONG $^{2}$, MEIXIN LIANG $^{1}$ and JIAN GE $^{1}$ \\ ${ }^{1}$ State Key Laboratory of Ophthalmology, Zhongshan Ophthalmic Center, Sun Yat-sen University, Guangzhou, \\ Guangdong 510060; ${ }^{2}$ The First Affiliated Hospital of Kunming Medical University, Kunming, Yunnan 650031, P.R. China
}

Received November 12, 2016; Accepted June 30, 2017

DOI: $10.3892 / \mathrm{ijmm} .2017 .3058$

\begin{abstract}
The pathogenesis of Rb1 gene inactivation indicates that gene therapy could be a promising treatment for retinoblastoma. An appropriate gene transfer system is the basis for successful gene therapy; however, little attention has been given to an effective gene transfer system for retinoblastoma therapy in previous studies. This study was designed to provide an optimized transgene system for WERI-Rb1 cells (W-RBCs). Green fluorescent protein (GFP) was adopted as a reporter. Four classic viral vectors based on retroviruses, recombinant adeno-associated viruses (rAAV2, rAAV2/1), lentiviruses (LVs) and a novel non-viral vector X-treme HP reagent were adopted for W-RBC gene transfection. The efficacy and cytotoxicity were comprehensively compared among the different vectors through GFP expression and the trypan blue exclusion test. Furthermore, the serum and cell culture status were also optimized for better transfection. Cells transfected by rAAV2/1 expressed more GFP protein and exhibited less staining with trypan blue, compared to the rAAV2 counterpart. However, in comparison to the retroviral group, both the rAAV2/1 and LV groups had considerably less $\mathrm{GFP}^{+}$cells. Interestingly, the X-treme HP presented a similar GFP transfection capacity to the retroviral vector, but with a much lower cytotoxicity. Furthermore, there were more $\mathrm{GFP}^{+}$cells in a suspended condition than that in an adherent culture. Moreover, cells in a serum-positive system expressed more GFP, while cells in a serum-free system showed lower GFP expression and higher cytotoxicity. In conclusion, the retroviral vector and the $\mathrm{X}$-treme HP are effective for W-RBC gene transfection, while the X-treme HP is more preferable due to its lower cytotoxicity. Moreover, the suspended cell culture system is superior to the adherent system, and the serum protects cell viability and facilitates the gene transfection of W-RBCs. This study presents an effective, convenient, and low toxic transfection system for gene delivery in W-RBCs and provides a promising system for further gene therapy of retinoblastoma.
\end{abstract}

Correspondence to: Professor Jian Ge, State Key Laboratory of Ophthalmology, Zhongshan Ophthalmic Center, Sun Yat-sen University, 54S Xian Lie Road, Guangzhou, Guangdong 510060, P.R. China

E-mail: gejian@mail.sysu.edu.cn

Key words: gene transfection, retinoblastoma, vector

\section{Introduction}

Retinoblastoma is the most frequent intraocular malignancy in children, with a worldwide incidence of 1/16,000-1/18,000 live births (1). Although current therapies have achieved considerable improvements, there are still unsolved issues: secondary tumor growth (2), optic nerve damage (3), and normal retina impairment caused by nonspecific chemotherapy and radiation $(4,5)$.

A novel therapy for tumors is gene therapy. Compared with conventional therapies, gene therapy has exhibited several advantages, such as specific regulation and a longstanding effect in a controlled manner. There have been 2,388 clinical trials that have investigated gene therapy for several tumors or cancers, such as brain tumors, breast cancer, and prostate cancer. Among the 699 completed trials, many have shown the effectiveness of gene therapy as a valuable supplement and even a novel approach to tumor/cancer therapy.

Inactivation of the Rb1 gene alley, the major cause of retinoblastoma, has made gene therapy a promising treatment for retinoblastoma patients. In fact, several types of genes, including the suicide gene (e.g., HSV-TK/GCV) $(6,7)$, antioncogenes (e.g., Rb1, P21 and P53) (8,9), and anti-angiogenesis genes (e.g., sFlk21 and ExTek) $(10,11)$, have been transfected into retinoblastoma cells to inhibit their proliferation or to induce their apoptosis.

Successful gene therapy is based on an appropriate transgene vector; however, previous studies have mainly focused on the function of transgenes rather than the vectors. A few types of transgene vectors have been randomly adopted for retinoblastoma gene transfection, including the adenoviral vector $(6,7)$, the liposome (12), and some uncommon vectors such as the encephalomyocarditis virus (13). There is no systemic evaluation of these vectors, and there is also a lack of evaluation of other vectors that are utilized more often. Thus, it is crucial to systematically optimize proper gene vectors for retinoblastoma cells.

Generally, the present gene vectors are classified as viraland non-viral vectors. Various viral vectors have been adopted to transfect the retina. Among them, vectors based on retroviruses, recombinant adeno-associated viruses (rAAVs), and lentiviruses (LVs) are the most commonly used. These vectors were assumed to be effective in retinoblastoma transfection, considering the retinal origin of retinoblastoma $(14,15)$.

The retroviral vector has been considered as a preferred gene transfer system. It can insert the transgene into the 
dividing cell chromosome to ensure stable transmission to daughter cells for long-term therapy. Researchers have utilized the retroviral vector to restore the $\mathrm{Rbl}$ gene into the retinoblastoma cell line Y79 to prevent tumor cell proliferation (16). Unlike retroviruses, the rAAVs, a parvovirus, can infect both dividing and non-dividing cells but do not integrate into the host genome. They are divided into 12 serotypes (17), and serotype 2 is the most well-known and commonly used in retina research. rAAV2 was confirmed to efficiently transfect both retinal pigment epithelium (RPE) cells (18) and photoreceptors without obvious toxicity $(19,20)$. In addition, it has been used in an increasing number of clinical trials of retinal degeneration diseases, such as Leber's congenital amaurosis type 2 (LCA2) (21), age-related macular degeneration (AMD) (22), and choroideremia (23). The exchange of capsids in rAAV serotypes results in distinct transduction in various retinal cell types. The rAAV2/1, containing a rAAV2 genome in one rAAV2 capsid, was reported to efficiently transfect the retina (24). Another viral vector that can transfect post-mitotic cells is the LV, which has a larger payload capacity ( $\sim 9 \mathrm{~kb})$ than rAAV $(\sim 4.7 \mathrm{~kb})(25)$. Moreover, it can drive prolonged and stable transgene expression in the retina, brain, and even various stem/progenitor cells by genome integration (26). It was published that $>80 \%$ photoreceptors expressed green fluorescent protein (GFP) for at least 12 weeks following HIV-based LV vector transfection (27).

Non-viral vectors have several advantages over viral vectors due to their low pathogenicity, low immunotoxicity, and ease of production, despite their relatively lower transfection efficiency. These vectors are broadly classified as naked/plasmid DNA, physical-based and chemical-based vectors. The application of naked/plasmid DNA is limited by low efficiency. Physical-based vectors, such as electroporation and ultrasound microbubbles, are primarily limited by cell damage and low efficiency. Conventional chemical-based vectors, such as lipoplexes, have been used for retina and RPE gene delivery (28), however, their transfection efficiencies are very low due to their positive charges, which are greatly affected by the negatively charged protein in serum. Here, we adopted a neotype lipid vector, the X-treme HP reagent, for WERI-Rb1 cell transfection because of its improved efficiency and safety in several cell lines that are difficult to transfect, such as human umbilical cord blood mesenchymal stem cells.

In addition to the vector, successful gene transfection is also based on the cell culture system. Currently, most of the transfection experiments have performed well in a serumfree medium in vitro; however, a high transfection efficiency in the presence of serum is desirable since serum starvation can affect the cell cycle and viability. Moreover, serum interference cannot be avoided in vivo. In addition to serum, the cell culture status affects gene transduction efficiency as well. Vectors perform differently in suspension or in adherent cells. Retinoblastoma cells are usually suspended and form rosettes or grape-like cell clusters, which hinder the attachment of transgenes with the inner cells wrapping in clusters. In contrast, an adherent culture may extend gene exposure and avoid a chromosomal positional effect. Thus, we examined whether the adherence of retinoblastoma cells would benefit transfection.
This study was designed to optimize a gene transfection system specific for retinoblastoma. The classic retinoblastoma cell line, WERI-Rb1 (W-RBCs), was selected as host cells, and the GFP DNA was adopted as the reporter gene. We systemically tested the efficacy and cytotoxicity of different viral and non-viral vectors for GFP transfection and further explored the potential effect of serum and the cell culture system on GFP transfection. This study presents an efficient and low cytotoxic system for retinoblastoma gene transfection and could provide a promising transgene system for further gene therapy of retinoblastoma.

\section{Materials and methods}

Cell culture. The human retinoblastoma cell line WERI-Rb1 (American Type Culture Collection, Manassas, VA, USA) was suspended in RPMI-1640 medium (HyClone, Logan, UT, USA) with $10 \%$ fetal bovine serum (FBS; Gibco, Carlsbad, CA, USA). Fresh medium was exchanged $24 \mathrm{~h}$ after thawing cells. Three to 4 days later, cells were passaged to single cells by gentle mechanical dissociation and reseeded at a density of $10^{5}$ cells $/ \mathrm{ml}$. All cells were cultured at $37^{\circ} \mathrm{C}$ in an atmosphere with $5 \% \mathrm{CO}_{2}$ and observed under an inverted microscope every other day.

An Ecopack2-293 packaging cell line (Clontech, Mountain View, CA, USA) was cultured in a 293 culture medium, consisting of Dulbecco's modified Eagle's medium (DMEM), $10 \%$ FBS, L-glutamine ( $2 \mathrm{mM})$, non-essential amino acids (NEAA, $0.1 \mathrm{mM}$ ) (all from Gibco), sodium pyruvate $(1 \mathrm{mM})$, and penicillin/streptomycin $(100 \mu \mathrm{g} / \mathrm{ml})$ (both from Sigma-Aldrich, St. Louis, MO, USA). The cells were exchanged in fresh medium every 2-3 days and passaged at 70-80\% confluence.

Cell adherence. For adherent transfection, the culture dish was pre-coated with $0.1 \mathrm{mg} / \mathrm{ml}$ poly D-lysine (PDL; Sigma-Aldrich) at $37^{\circ} \mathrm{C}$. After $24 \mathrm{~h}$, the PDL diluent was removed, and the dish was washed with phosphate-buffered saline (PBS) once. The W-RBC suspension was centrifuged at $157 \mathrm{x} \mathrm{g}$ for $10 \mathrm{~min}$, and then the cell precipitations were resuspended in a W-RBC culture medium, placed onto PDL-coated plates, and cultured at $37^{\circ} \mathrm{C}$ in an atmosphere with $5 \% \mathrm{CO}_{2}$.

Plasmid prep. GFP plasmid preps were performed using Qiagen Plasmid Hispeed Midi kit (Qiagen, Valencia, CA, USA) following the manufacturer's recommended protocol.

Retroviral packaging and transfection of suspended W-RBCs. The Ecopack 2-293 cells with 70-80\% cell fusion cultured in a $60-\mathrm{mm}$ dish were transfected using a transfection mixture consisting of pVPack-GP GP $(2.5 \mu \mathrm{g})$, pVPack-VSV-G $(1.5 \mu \mathrm{g})$, pMX-IRES-GFP $(4 \mu \mathrm{g})$ (all from Agilent Technologies, Santa Clara, CA, USA) and transfection reagent Fugene-HD (20 $\mu \mathrm{l}$ ). Fresh medium was exchanged $16 \mathrm{~h}$ after incubation. After $48 \mathrm{~h}$, the retrovirus containing supernatants was collected and filtered using a $0.45-\mu \mathrm{m}$ cellulose acetate membrane (Sartorius, Göttingen, Germany) and then centrifuged $(5,000 \mathrm{x} \mathrm{g})$ in $100 \mathrm{kDa}$ ultrafiltration tube (Millipore, Temecula, CA) for $30 \mathrm{~min}$ at $4^{\circ} \mathrm{C}$. The preintegration complex $(1 \mathrm{ml})$ was collected and added along with polybrene $(4 \mu \mathrm{g} / \mathrm{ml})$ 
in $1 \mathrm{ml}$ of suspended W-RBCs at a cell density of $7.5 \times 10^{4} / \mathrm{ml}$. Twenty-four hours later, the cells were resuspended in fresh medium and observed by an inverted microscope and fluorescence microscopy (Carl Zeiss, Inc., Oberkochen, Germany).

Recombinant adeno-associated virus transfection of suspended $W$-RBCs. The plasmids rAAV2-GFP $\left(2.5 \times 10^{11} \mu \mathrm{g} / \mathrm{ml}\right)$ and $\mathrm{rAAV} 2 / 1-\mathrm{GFP}\left(5 \times 10^{11} \mu \mathrm{g} / \mathrm{ml}\right)$ were constructed by Vector Gene Technology Company (VTGC, Beijing, China). The transient transfection of GFP into W-RBCs by rAAV was carried out according to the manufacturer's instructions. Briefly, $1.5 \times 10^{4} \mathrm{~W}-\mathrm{RBCs}$ per milliliter of serum/antibiotic-free medium were exposed to three different virus MOIs, respectively: $10^{6}, 10^{5}$ and $10^{4}$. Two hours later, the cells were re-cultured in fresh medium at $37^{\circ} \mathrm{C}$ in an atmosphere with $5 \% \mathrm{CO}_{2}$. Cells were evaluated each day using an inverted microscope, and GFP fluorescence was observed under fluorescence microscopy (both from Carl Zeiss).

Lentiviral transfection of suspended W-RBCs. Three hours prior to transfection, $5 \times 10^{4} \mathrm{~W}$-RBCs were cultured in $1 \mathrm{ml}$ serum/ antibiotic-free medium. The LVs $\left(1.4 \times 10^{8} \mathrm{TU} / \mathrm{ml}\right)(\mathrm{VTGC})$ with different MOIs (2 and 10) were respectively added into two cell groups in three reduplications. Cells were cultured at $37^{\circ} \mathrm{C}$ in an atmosphere with $5 \% \mathrm{CO}_{2}$ for $16 \mathrm{~h}$ and recultured in fresh medium. Cells were evaluated each day using an inverted microscope, and GFP fluorescence was observed under fluorescence microscopy (both from Carl Zeiss).

$X$-treme HP transfection with/without FBS. Transfection with X-treme Gene HP DNA transfection reagent (Roche, Basel, Switzerland) was performed on both suspended and adherent W-RBCs following manufacturer's instructions. Briefly, DNA was diluted with a serum-free medium to a final concentration of $1 \mu \mathrm{g}$ plasmid DNA/100 $\mu \mathrm{l}$ medium $(0.01 \mu \mathrm{g} / \mu \mathrm{l})$. For the transfection with FBS, the X-treme Gene HP DNA transfection reagent was pipetted directly into the culture medium containing the diluted DNA with a ratio of 1:1 of X-treme reagent $(\mu \mathrm{l})$ to plasmid DNA $(\mu \mathrm{g})$. For the transfection without FBS, the cell culture medium was replaced with a serum/antibioticfree RPMI-1640 medium $3 \mathrm{~h}$ before adding the reagent-DNA mixture. The transfection reagent and DNA complex were incubated for $15 \mathrm{~min}$ at +15 to $+25^{\circ} \mathrm{C}$. The transfection complex was then added into $5 \times 10^{4}$ suspended and adherent W-RBCs in a dropwise manner. The removal of growth medium was not necessary. Following transfection, the cells were incubated for $24 \mathrm{~h}$ before consequent GFP expression measurement.

Transfection efficiency analysis. The analysis of the transfection efficiency was carried out using the following 2 methods:

i) Fluorescence microscopy. GFP protein expression of the transfected cells was observed on different days. Fluorescence microscopy was performed using a fluorescence microscope (Carl Zeiss), and images were recorded using AxioVision software. GFP fluorescence was measured employing a wavelength filter set at 10 (Carl Zeiss MicroImaging, Goettingen, Germany). The results are expressed as the average percentage of GFP-positive cells/image, as indicators of transfection efficiency. The transfection efficiency of each protocol was compared. ii) Fluorescence-activated cell sorter (FACS) analysis. GFP expression of the transfected cells was investigated by a fluorescence-activated cell sorter to determine the transfection efficiency of each protocol. Single transfected W-RBCs and untransfected W-RBCs were respectively resuspended in FACS analysis buffer (PBS, 0.5\% BSA, 2 mM EDTA$\left.2 \mathrm{Na}-2 \mathrm{H}_{2} \mathrm{O}\right)$. The percentages of $\mathrm{GFP}^{+}$cells were assessed by comparing the different transfected groups to untransfected cells by flow cytometry (FACSAria; BD Biosciences, Franklin Lakes, NJ, USA).

Cell viability analysis. Viable cells were counted with a hemocytometer using the standard trypan blue exclusion test (0.4\% trypan blue; Sigma-Adrich), as previously reported (29). Briefly, the W-RBC suspension (10 $\mu \mathrm{l})$ was mixed with trypan blue $(90 \mu \mathrm{l})$ and incubated for $2 \mathrm{~min}$ at room temperature. Then, $10 \mu \mathrm{l}$ of the cell suspension was dropped on the hemocytometer, which counted the viable and dead (blue) cells in 25 medium-sized squares. The total number of viable cells was calculated by determining the number of live cells $\mathrm{x}$ dilution factor $\mathrm{x} 10^{4} \mathrm{x}$ total volume (ml). Viability (\%) equals the number of live cells/(number of live cells + number of dead cells) $\mathrm{x} 100 \%$.

Statistical analysis. Each experiment was performed in triplicate. All data are represented as the mean \pm standard deviation (SD). Significance was assessed with the Student's t-test for the comparison of two variables, or with a one-way or two-way ANOVA for multivariable comparisons using SPSS 13.0 (IBM, Armonk, NY, USA). A value of $\mathrm{P}<0.05$ was considered significant.

\section{Results}

Recombinant adeno-associated virus transduction of $W$-RBCs. Two different rAAV vectors (rAAV2/1 and rAAV2) were applied to test whether the $\mathrm{AAAV}$ vectors could efficiently transfect W-RBCs. Three different MOIs $\left(10^{4}, 10^{5}\right.$ and $\left.10^{6}\right)$ were also compared in both rAAVs for optimization. The transfected W-RBCs expressed negative GFP during the first $48 \mathrm{~h}$ after transfection (data not shown). The flow cytometric analysis showed a markedly low $\mathrm{GFP}^{+}$cell rate, which ranged from 0 to $0.3 \%$ in both AAVs with the three MOI transfected groups at $72 \mathrm{~h}$ (Fig. 1-A1 and A3); however, on the 10th day, all transfected groups had generally improved GFP expression. Specifically, the rAAV2 with the $10^{5} \mathrm{MOI}$ group presented more $\mathrm{GFP}^{+}$cells $(0.8 \%)$ compared to the other two rAAV2 groups with different MOIs $\left(10^{4}, 0.4 \% ; 10^{6}, 0.6 \%\right)$ (Fig. 1-A4) and the rAAV2/1 group with the same MOI $\left(10^{5}, 0.7 \%\right)$ (Fig. 1-A2). Notably, cells transfected with the lowest MOI $\left(10^{4}\right)$ by rAAV2/1 induced the highest GFP expression (1.6\%) among all experimental groups (Fig. 1-A2). The immunofluorescence assay indicated that the rAAV2/1-mediated transfection induced more W-RBCs to express GFP protein compared to rAAV2, despite having three MOIs. The percentage of $\mathrm{GFP}^{+}$cells in both rAAVs-treated groups on the 10th day also confirmed that the $\mathrm{rAAV} 2 / 1$ with the $10^{4} \mathrm{MOI}$ induced considerably more $\mathrm{GFP}^{+}$cells than the other groups. We further investigated the cell viability by trypan blue staining 10 days after transfection. We found that the cell survival rates of both rAAV-treated 
A
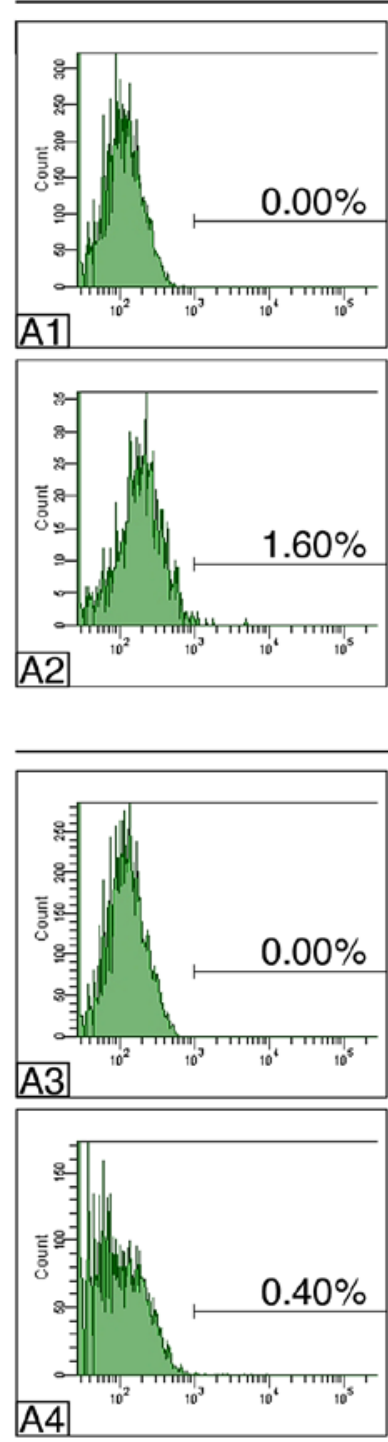

B

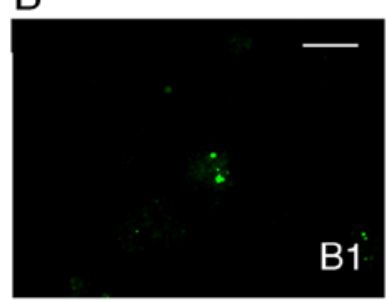

B1

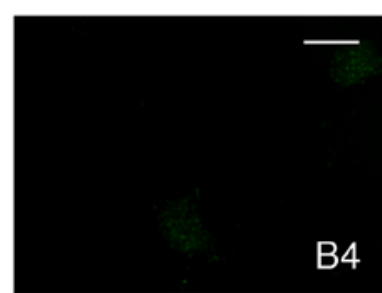

rAAV2/1
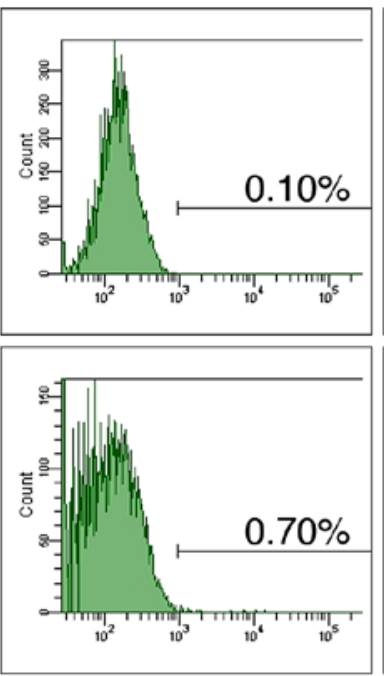

rAAV2
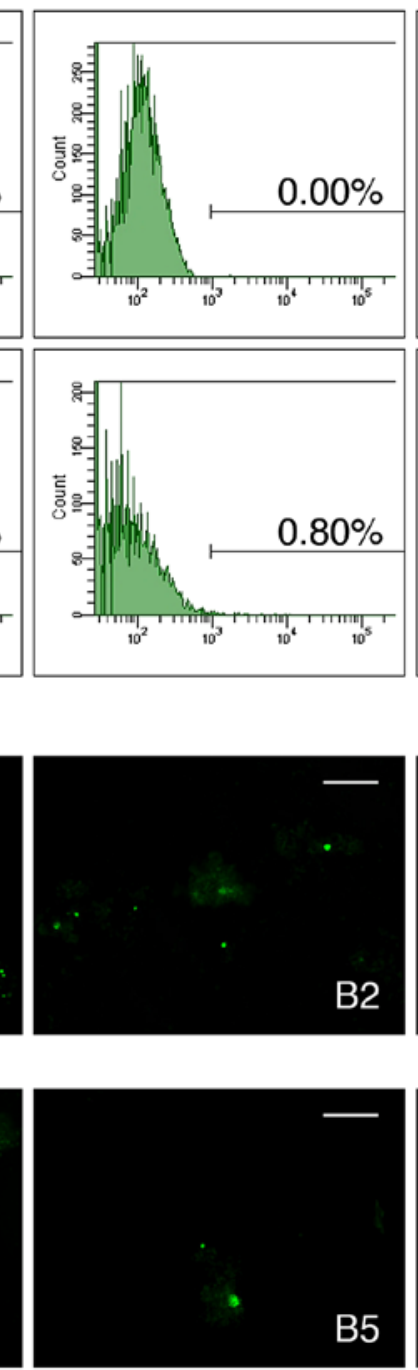
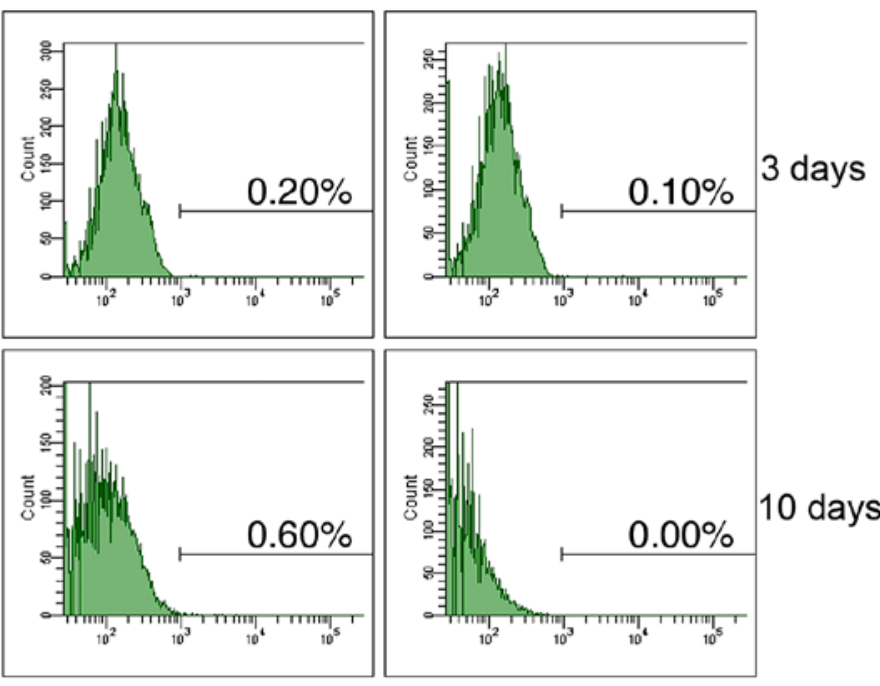

Control
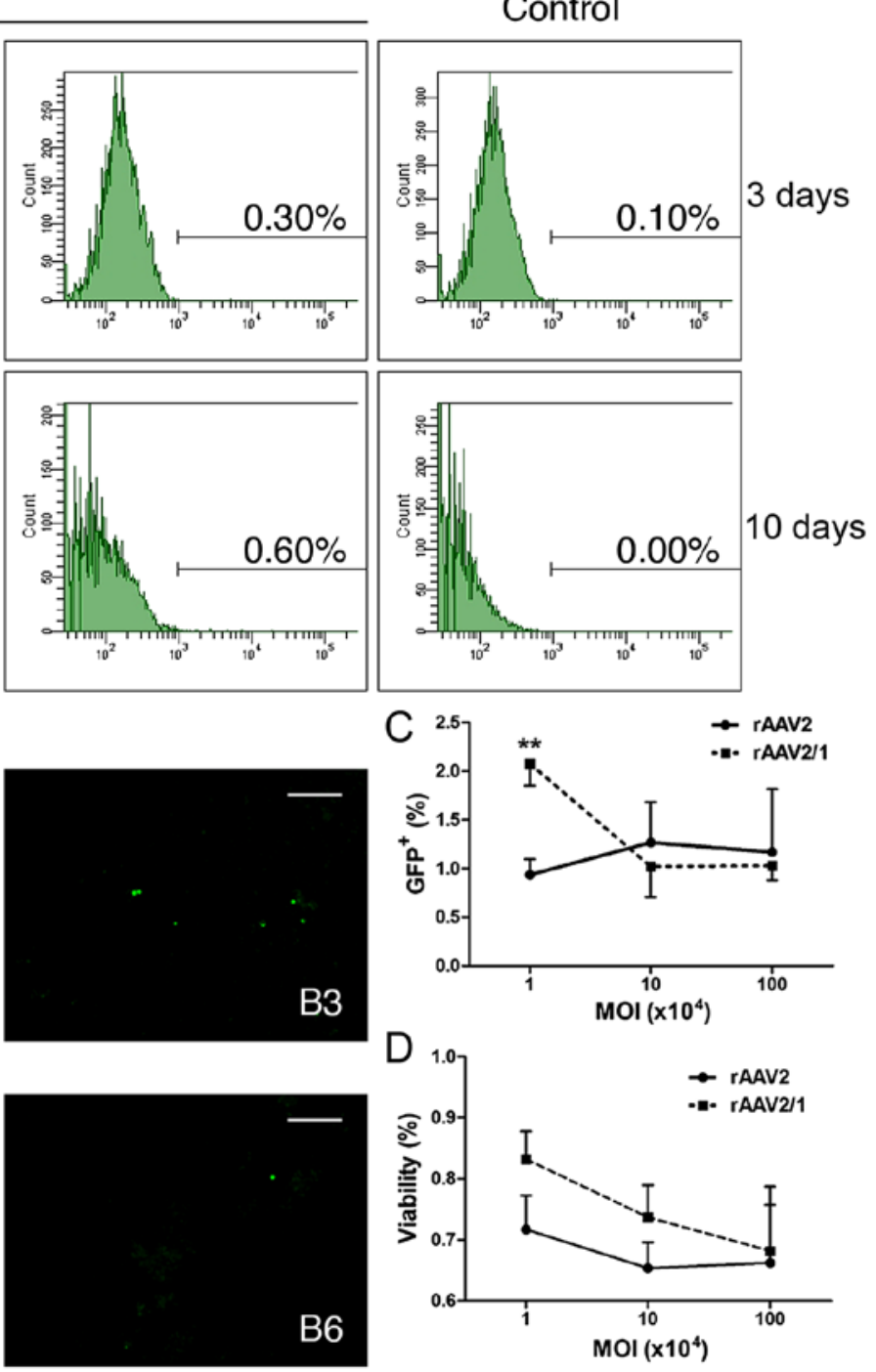

Figure 1. Recombinant adeno-associated virus transduction of WERI-Rb1 cells (W-RBCs). (A) The percentages of green fluorescent protein (GFP) ${ }^{+}$cells were assessed by FACS in recombinant adeno-associated virus (rAAV)2/1 (A1 and A2) and rAAV2 (A3 and A4)-transfected groups and untransfected W-RBCs (control) at the 3rd (A1 and A3) and the 10th (A2 and A4) day, with different MOIs $\left(10^{4}, 10^{5}\right.$ and $\left.10^{6}\right)$, respectively. The percentages were markedly low in both rAAVs at the 3rd day and slightly increased at the 10th day. Notably, cells transfected with the lowest MOI (10 $)$ by rAAV2/1 induced the highest GFP expression (1.6\%). (B) Immunofluorescence assay evaluated the GFP expression in rAAV2/1 (B1-B3) and rAAV2 (B4-B6) groups at the 10th day with different MOIs (10 ${ }^{4}, 10^{5}$ and $10^{6}$ ), respectively. Higher GFP expression was observed in the rAAV2/1-mediated transduction groups. (C) The percentage of GFP ${ }^{+}$cells was higher in rAAV2/1treated group than in the rAAV2 group at the 10th day at MOI $\left(10^{4}\right)$. (D) Cell viability was tested by trypan blue 10 days after transfection. Cell survival rates declined in an MOI-dependent manner, and more cells survived in the rAAV2/1-treated group with $10^{4} \mathrm{MOI}\left[(\mathrm{C}){ }^{* *} \mathrm{P}<0.01, \mathrm{n}=3\right.$; $\left.(\mathrm{D}) \mathrm{n}=4\right]$. Scale bars, $400 \mu \mathrm{m}$. 


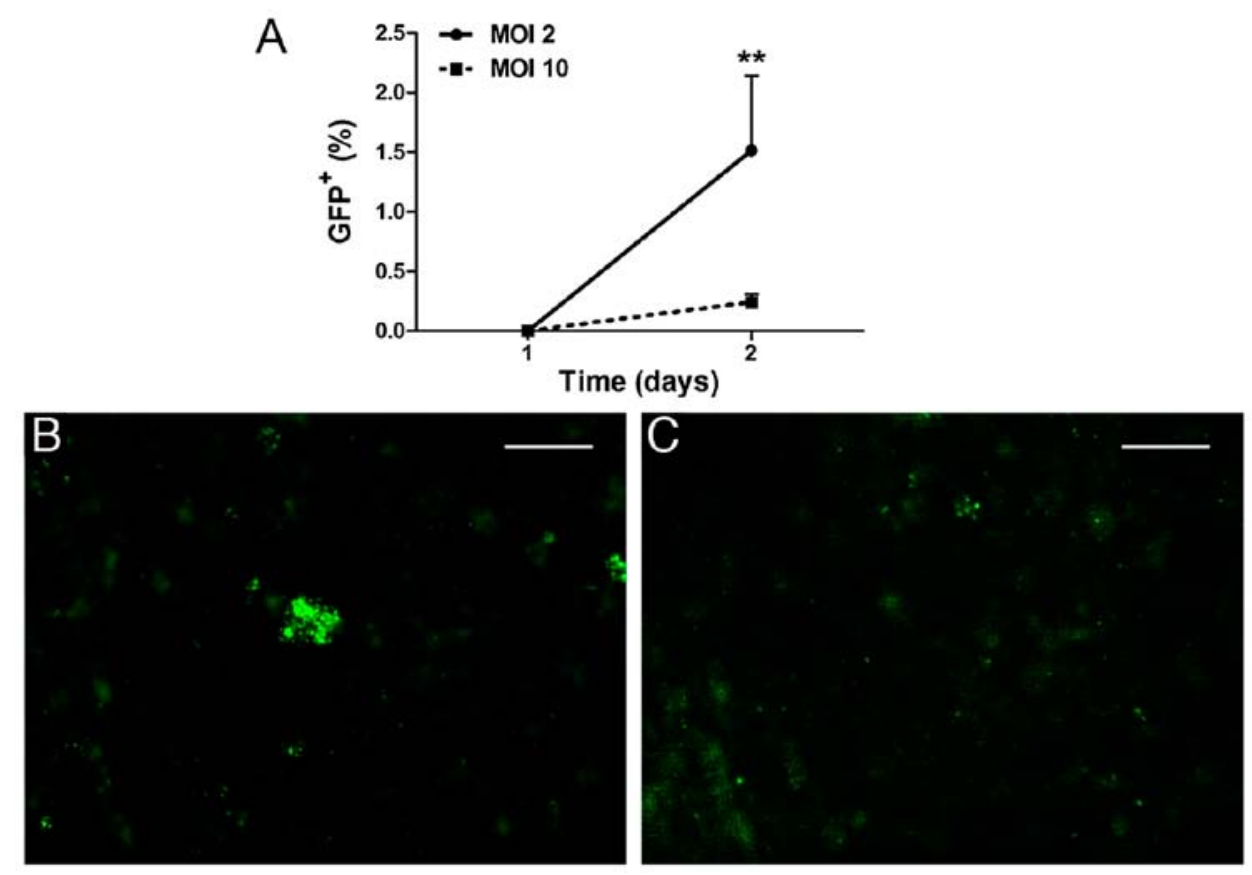

Figure 2. Lentiviral transduction of WERI-Rb1 cells (W-RBCs). (A) Percentage of green fluorescent protein (GFP) $)^{+}$cells at two different MOIs (2 and 10) of lentiviral vectors at the 1 st and the 2 nd day. (B and C) The immunofluorescence presented a relatively higher intensity of GFP staining in the MOI 2 group (B) compared to MOI 10 (C) 2 days after transfection $\left({ }^{* *} \mathrm{P}<0.01, \mathrm{n}=3\right)$. Scale bars, $400 \mu \mathrm{m}$.

groups declined in an MOI-dependent manner with a higher cell survival at the lower MOI. Interestingly, the rAAV2/1-treated groups, especially the group with $10^{4} \mathrm{MOI}$, showed higher viability than the rAAV2-treated groups, although there was no significant difference. These results showed the relative effectiveness and the low cytotoxicity of rAAV2/1 transfection with $10^{4} \mathrm{MOI}$; however, both rAAV vectors showed poor efficacies.

Lentiviral transduction of $W$-RBCs. LVs are effective for transfecting both dividing and non-dividing cells. Hence, we evaluated whether LVs could effectively drive the GFP plasmid into W-RBCs as well. Two different MOIs (2 and 10) were adopted for optimization. The transfected W-RBCs expressed no positive GFP on the 1st day after transfection. Two days later, cells begun to express GFP protein, and the MOI 2 group showed significantly more $\mathrm{GFP}^{+}$cells with an average percentage of $1.52 \%$ /image, which was considerably more than the MOI 10 group ( 0.24\%/image) (Fig. $2 \mathrm{~A})$. The immunofluorescence also exhibited a relatively higher intensity of GFP staining in the cells treated by MOI 2 (Fig. 2B) compared to MOI 10 (Fig. 2C). Unfortunately, the efficiency of the LV vectors also remained at a low level.

Optimization of vectors in suspended $W$-RBCs. Given the poor performance of the $\mathrm{rAAV}$ and $\mathrm{LV}$ vectors, retrovirus vectors and a non-virus reagent (X-treme HP) were investigated for optimization. The data showed that the number of $\mathrm{GFP}^{+}$cells was remarkably higher when transfected by the retrovirus vectors and the X-treme HP reagent compared to the other three virus vectors (rAAV2/1, rAAV2 and LVs) both on the 1 st and the 5th day (Fig. 3A). Specifically, there were more $\mathrm{GFP}^{+}$cells in the retrovirus group than that in the X-treme HP group at the early phase of transfection (1 day). Four days later, the number of cells slightly decreased in both groups; however, no significant difference was found between the two groups. The immunofluorescence also showed a similar GFP intensity in both the retrovirus and X-treme HP groups at day 1 and 5 (Fig. 3B). Furthermore, the cell viability of X-treme HP on the 5th day presented a higher survival rate $(80.12 \%)$ compared to the retrovirus $(69.56 \%)$, and there was a significant difference in untransfected W-RBCs (92.93\%) (Fig. 3C). Taken together, the retrovirus and X-treme HP were more effective than rAAVs and LVs for W-RBC transfection, but given the severe cytotoxicity and complicated packaging of the retrovirus, the non-viral X-treme HP reagent was more favorable for transfecting suspended W-RBCs.

Comparison of serum-tolerant to serum-free transfection in suspended $W$-RBCs by $X$-treme HP reagent. We further explored whether there would be any differences under serum-tolerant and serum-free conditions by X-treme HP transfection. We found that the percentage of $\mathrm{GFP}^{+}$cells was $3.80 \%$ following serum-free transfection after $24 \mathrm{~h}$, and the percentage was higher than both the serum-tolerant transfection $(1.73 \%)$ and the untransfected control $(0.60 \%)$; however, only the latter showed a significant difference (Table I). Interestingly, over time, the serum-tolerant group (Fig. 4-A1) exhibited a progressive and significant increase in $\mathrm{GFP}^{+}$cells compared to the control (Fig. 4-A3) (Table I). Conversely, the $\mathrm{GFP}^{+}$cells in the serum-free group showed no significant increase during the $72 \mathrm{~h}$ (Fig. 4-A2 and Table I). Although the percentage of $\mathrm{GFP}^{+}$cells in the serum-free group was significantly higher than the control from day 1 to 3 , it was still markedly lower than that in the serum-tolerant group on the 3rd day (Fig. 4A and Table I). The immunofluorescence (Fig. 4B) and cell quantitative analysis (Fig. 4C) also presented progressively increased $\mathrm{GFP}^{+}$cells in the $\mathrm{FBS}(+)$ group during the 3 days post-transfection, whereas the $\mathrm{GFP}^{+}$ 
A

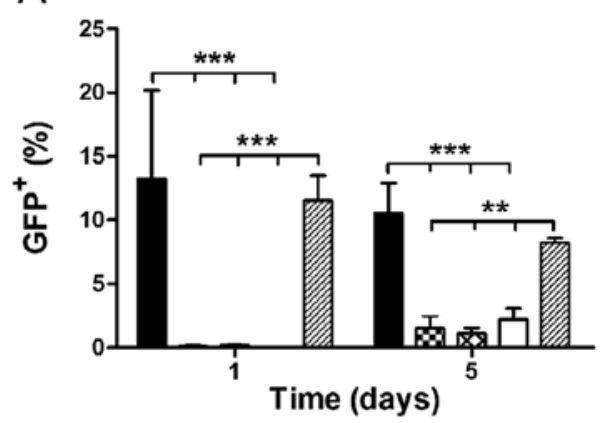

Retrovirus

$\$$ rAAV2/1

$\otimes$ rAAV2

$\square$ Lentivirus

X-treme HP

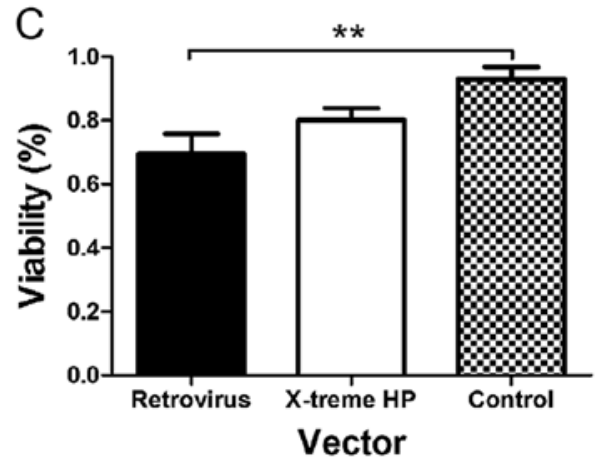

B
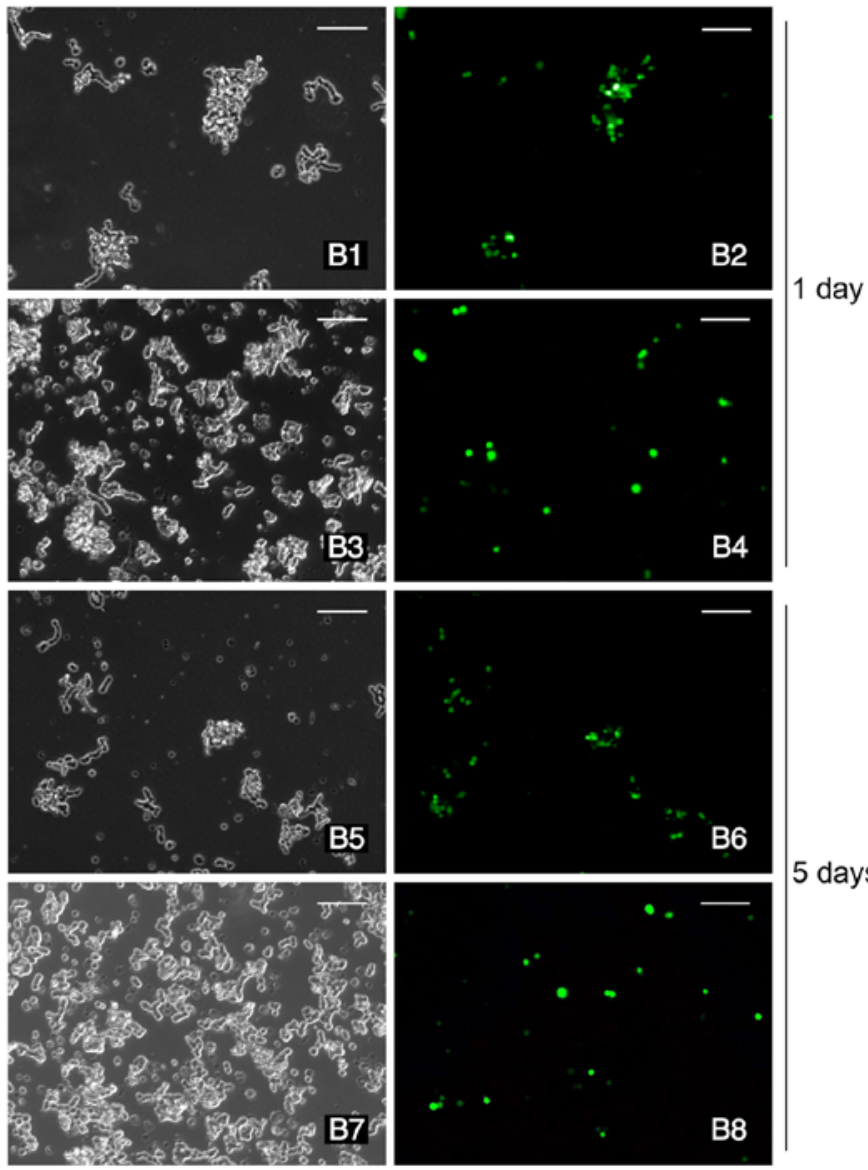

Figure 3. Optimization of the vectors transfecting suspended WERI-Rb1 cells (W-RBCs). (A) Comparison of the percentage of green fluorescent protein $(\mathrm{GFP})^{+}$cells among the 4 viral vectors and non-viral X-treme HP reagent groups at day 1 and 5. Much more cells expressed GFP protein when transfected by the retrovirus and X-treme HP compared to the other groups no matter at the 1st or the 5th day. (B) The immunofluorescence showed similar GFP expression between the retrovirus vector (B1-B2 and B5-B6) and X-treme HP (B3-B4 and B7-B8) at day 1 and 5. (C) Retroviral transfection induced significant cell death compared to untransfected W-RBCs (control), whereas the $\mathrm{X}$-treme HP transfected cells showed a higher survival rate $\left({ }^{* *} \mathrm{P}<0.01\right.$ and ${ }^{* * *} \mathrm{P}<0.001$; $=3$ ). Scale bars, $100 \mu \mathrm{m}$.

cells of the FBS(-) group sustained a low level during the same period. Moreover, there were significantly more cells that were positively stained by trypan blue in the serum-free group compared with that in the other two groups, which showed similar survival rates (Fig. 4D). The serum prevention of cytotoxicity was also observed in the phenotype of W-RBCs. The serum-tolerant transfected cells generated large grape-like cell clusters with the typical large stained nuclei of retinoblastoma cells 3 days later (Fig. 4-B4), whereas the serum-free transfected cells only grew small cell clusters with tiny soma, high photopermeability, small nuclei and large cytoplasm (Fig. 4-B8). These results indicated that serum benefited the X-treme HP transfection in suspended W-RBCs and could also effectively preserve cells from potential cytotoxicity during gene transduction.

Transfection of adherent $W$-RBCs. Given the high efficiency of the retrovirus and X-treme HP transfection in suspended $\mathrm{W}$-RBCs, these two vectors were also adopted for the transfection of adherent W-RBCs. The results were as follows:

i) Retroviral transfection. We observed the GFP expression during the post-transfection period ranging from 1 to 24 days and found that the cells expressing GFP protein remained at a low level within 5 days and then reached a peak $(\sim 24.96 \%)$ when extended to 9 days; however, for the long-term investigation (24 days), the number of $\mathrm{GFP}^{+}$cells decreased to the primary level ( 6.94\%) (Fig. 5A and B). It is notable that the cell survival rate of the retrovirus vector group was also found to significantly decrease (62.97\%) 24 days later compared with the blank control $(80.36 \%)$, even though the rate corresponded to the control on the 1st day (Fig. 5C).

ii) Comparison of serum-tolerant and serum-free transfection in adherent $W$-RBCs by $X$-treme HP reagent. For the $\mathrm{X}$-treme HP transfection of adherent W-RBCs, the serum effect was also evaluated. The immunofluorescence and $\mathrm{GFP}^{+}$ cell quantification exhibited that the GFP expression of the serum-tolerant group gradually increased from the 1st day to the 3rd day (Fig. 6-A1-A3 and B). In contrast, there was no significant increase in $\mathrm{GFP}^{+}$cells in the serum-free group, and it had remarkably fewer GFP cells than the serum-tolerant group on day 2 and 3, respectively (Fig. 6-A5-A7 and B). The FACS also showed a tendency of increasing $\mathrm{GFP}^{+}$cells from day 2 to 3, and the serum-tolerant cells expressed more GFP than the serum-free cells and the blank control; however, a significant difference was only observed between $\mathrm{FBS}(+)$ and the control on the 3rd day (Fig. 6C and Table II). For the cyto- 


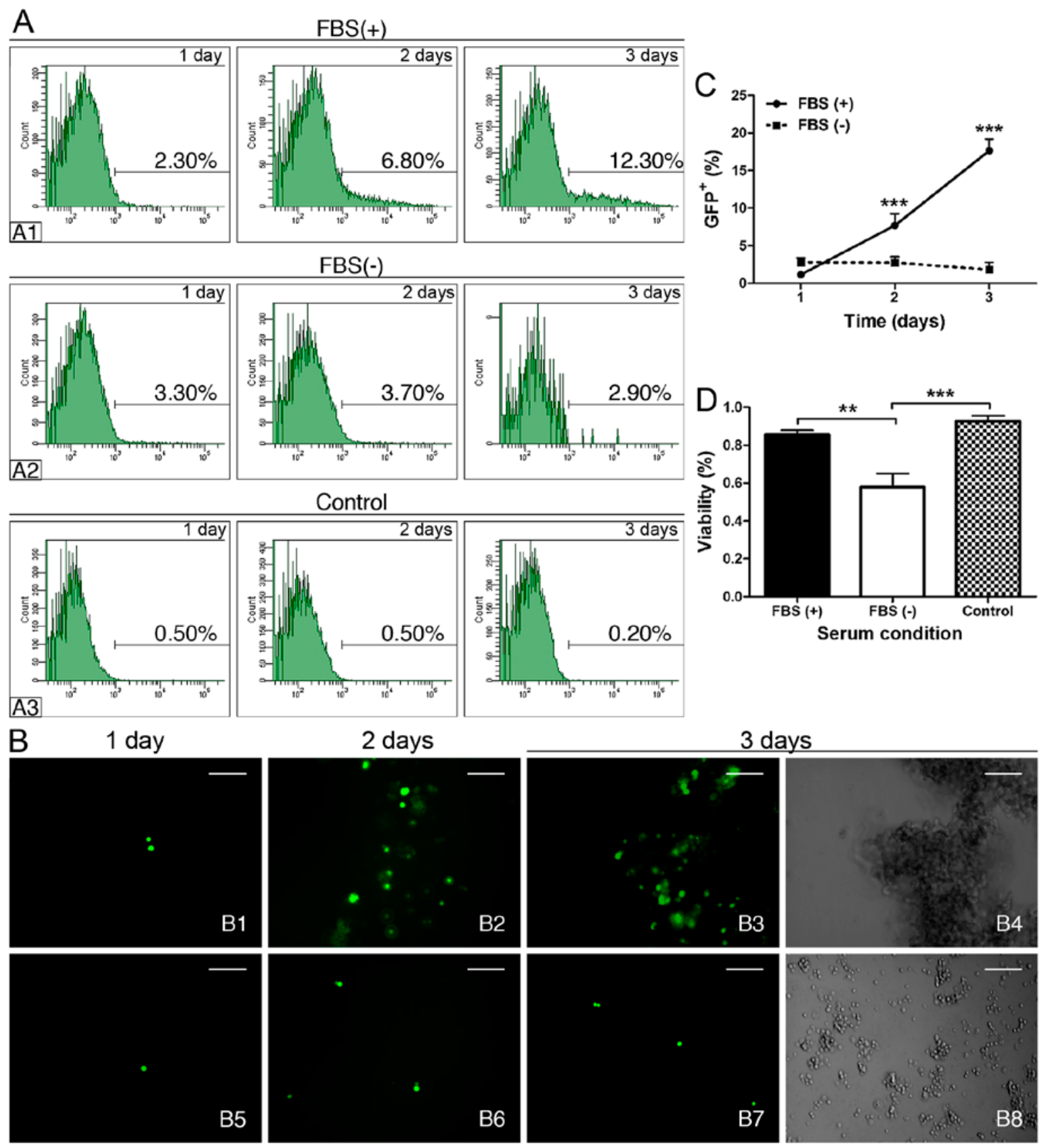

Figure 4. Comparison of serum-tolerant to serum-free transfection of suspended WERI-Rb1 cells (W-RBCs) by X-treme HP reagent. (A) FACS of the percentages of green fluorescent protein (GFP) ${ }^{+}$cells in FBS(+) (A1), FBS(-) (A2) and untransfected W-RBCs [control (A3)] from day 1 to day 3. At the 1st day, the transfected cells $\left(\mathrm{FBS}^{+-}\right.$) expressed more GFP compared with the control. But as time increased, the FBS(+) group exhibited a progressive and significant increase in $\mathrm{GFP}^{+}$cells compared with FBS(-), which was decreased compared with the control. (B and C) The immunofluorescence (B) and statistical analysis (C) showed progressively increased $\mathrm{GFP}^{+}$cells in the FBS(+) group (B1-B3) compared with the FBS(-) group (B5-B7) during the 3 days post transfection. In addition, cells exhibited cytotoxic phenotypes when serum was removed in transfection (B8) in contrast with serum-positive one (B4). (D) Less cells survived in the FBS(-) group compared with the other two groups $\left[{ }^{* *} \mathrm{P}<0.01 ;{ }^{* * *} \mathrm{P}<0.001\right.$; (C) $\mathrm{n}=4$; (D) $\left.\mathrm{n}=3\right]$. Scale bars, $100 \mu \mathrm{m}$.

toxicity analysis, the cells in serum-free conditions exhibited toxic phenotypes, as mentioned (Fig. 6-A8), and a significantly lower survival rate than the serum-tolerant group and the untreated control (Fig. 6D).

Comparison of suspended and adherent transfection in $W$-RBCs. In order to examine whether the cell culture status affects gene transfection, GFP expression was compared in both suspended and adherent cultured W-RBCs and the results were as follows: i) Retroviral transfection. Fig. 7A and B shows a significant difference in GFP expression between the two different cell culture systems at day 1 and 5. The retrovirus transfection was much more effective in the suspended W-RBCs (S-W-RBCs) than in the adherent W-RBCs (A-W-RBCs) (Fig. 7A) based on the fact that the $\mathrm{GFP}^{+}$percentage of $\mathrm{S}-\mathrm{W}-\mathrm{RBC}$ was significantly more than that of the A-W-RBCs at day 1, and also remained higher at day 5 , although without statistical difference. Flow cytometry was used to further investigate the GFP expression when the observation period was extended to 
A
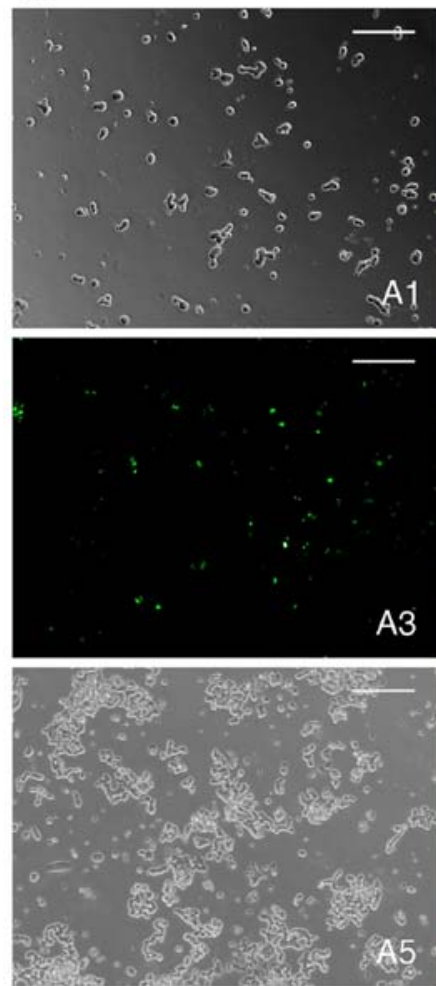
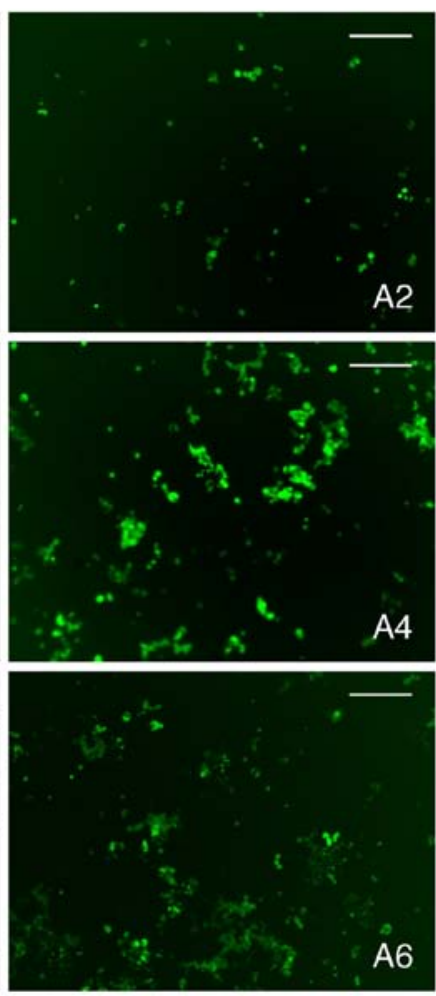

B
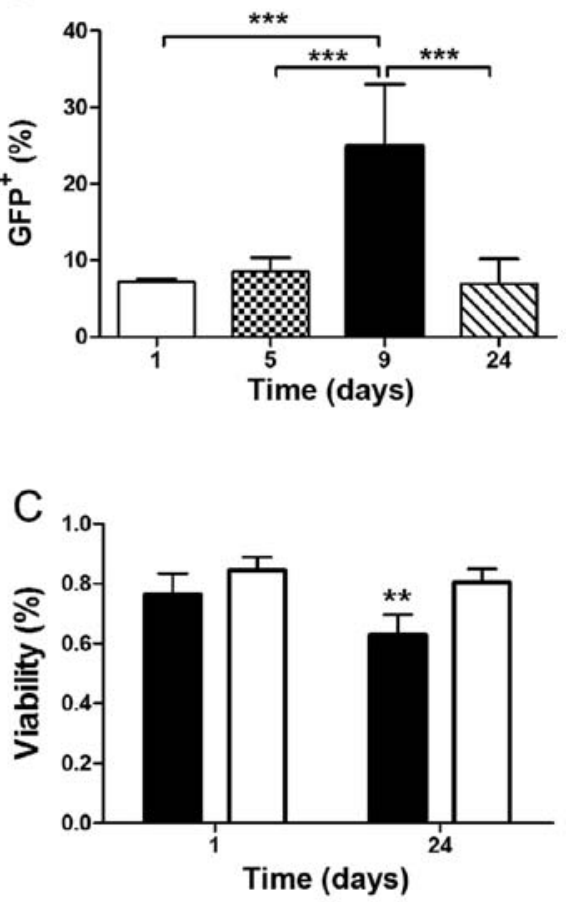

Retrovirus

$\square$ Control

Figure 5. Retroviral transfection of adherent WERI-Rb1 cells (W-RBCs). (A) Immunofluorescence presented different expression levels of green fluorescent protein (GFP) at day 1 (A1-A2), day 5 (A3), day 9 (A4) and day 24 (A5-A6). (B) Statistical analysis showed that a higher number of cells expressed GFP 9 days post transfection. (C) Cell survival rate in the retroviral vector group was significantly decreased 24 days later compared with the untransfected control $\left[{ }^{* *} \mathrm{P}<0.01\right.$ and $^{* * * *} \mathrm{P}<0.001$; (B) $\mathrm{n}=5$; (C) $\mathrm{n}=3$ ]. Scale bars, $200 \mu \mathrm{m}$.

Table I. Percentage of $\mathrm{GFP}^{+}$cells in different serum conditions in suspended W-RBCs by X-treme HP reagent as evaluated by FACS.

\begin{tabular}{lcrr}
\hline & FBS $(+)(\%)$ & FBS(-) $(\%)$ & Control $(\%)$ \\
\hline 1 day & $1.73 \pm 0.51$ & $3.80 \pm 0.50^{\mathrm{a}}$ & $0.60 \pm 0.10$ \\
2 days & $5.23 \pm 1.37^{\mathrm{b}}$ & $4.73 \pm 1.31^{\mathrm{a}}$ & $0.73 \pm 0.21$ \\
3 days & $12.27 \pm 3.55^{\mathrm{c}, \mathrm{d}}$ & $3.9 \pm 1.48^{\mathrm{a}}$ & $0.27 \pm 0.12$ \\
\hline
\end{tabular}

Cells expressed more GFP protein in the serum-free group than in the serum-tolerant and control groups within the first $24 \mathrm{~h}$; however, the serum-tolerant group exhibited a progressive and significant increase in $\mathrm{GFP}^{+}$cells compared to the serum-free and control within 3 days post transfection $\left[\mathrm{n}=3 ;{ }^{\mathrm{a}} \mathrm{P}<0.05,{ }^{\mathrm{b}} \mathrm{P}<0.01\right.$ and ${ }^{\mathrm{c}} \mathrm{P}<0.001, \mathrm{FBS}(+/-)$ vs. the control; ${ }^{\mathrm{d}} \mathrm{P}<0.001, \mathrm{FBS}(+)$ vs. $\left.\mathrm{FBS}(-)\right]$.

24 days. There were $38.8 \%$ S-W-RBCs that expressed positive GFP on the 5 th day, which was more than the adherent $(29.3 \%)$ and control $(0.4 \%)$. Interestingly, the $\mathrm{GFP}^{+}$cell percentage of suspended cells just slightly decreased to $31.2 \%$ 24 days later, which was still much higher than the other two groups (Fig. 7C).

ii) X-treme HP transfection. We confirmed that serum could benefit X-treme HP transfection and prevent cell death; hence, the serum-tolerant system was selected to compare X-treme HP transfection in suspended and adherent W-RBCs. Both of the two groups (suspended/adherent) had a progressive
Table II. Percentage of $\mathrm{GFP}^{+}$cells in the different serum conditions in adherent W-RBCs by X-treme HP reagent as evaluated by FACS.

\begin{tabular}{lllc}
\hline & FBS $(+)(\%)$ & FBS(-) $(\%)$ & Control (\%) \\
\hline 2 days & $1.37 \pm 1.14$ & $0.47 \pm 0.31$ & $0.3 \pm 0.2$ \\
3 days & $3.57 \pm 2.27^{\mathrm{a}}$ & $2.10 \pm 1.91$ & $0.3 \pm 0.1$ \\
\hline
\end{tabular}

The number of $\mathrm{GFP}^{+}$cells was increased in both serum-tolerant and serum-free cells from day 2 to day 3 , with the former showing a significant difference compared to the control at the 3rd day $[n=3$, ${ }^{\mathrm{a}} \mathrm{P}<0.05, \mathrm{FBS}(+/-)$ vs. the control].

increase in GFP expression from day 1 to 3, and the suspended groups presented a higher increase compared with the adherent group. More cells expressed GFP protein by suspended transfection than by adherent transfection at day 2 and 3, which showed significant differences (Fig. 8).

\section{Discussion}

Although comprehensive therapies contribute to a significant improvement in the retinoblastoma survival rate, tumor recurrence and extended impairment of neighboring tissues caused by traditional therapies cannot be avoided. Gene therapy would be a promising technique to targetly correct the gene defects of retinoblastoma; however, little attention has been paid to 
A
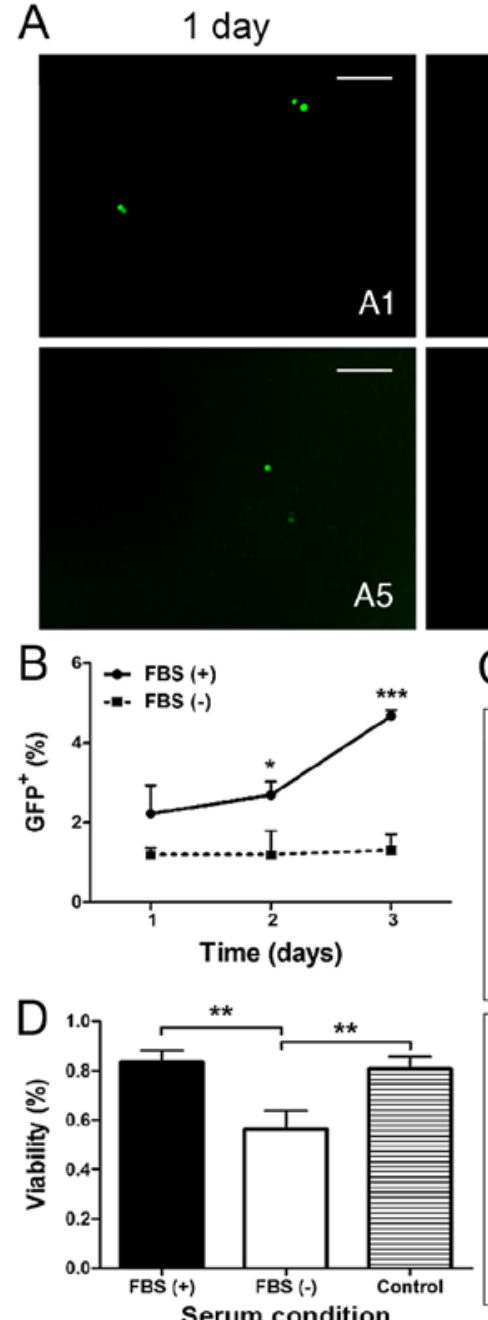

2 days

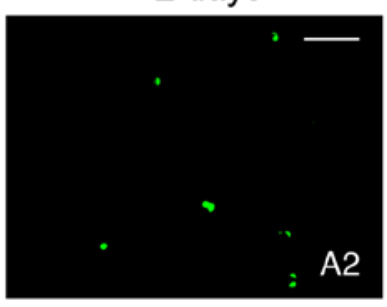

A2
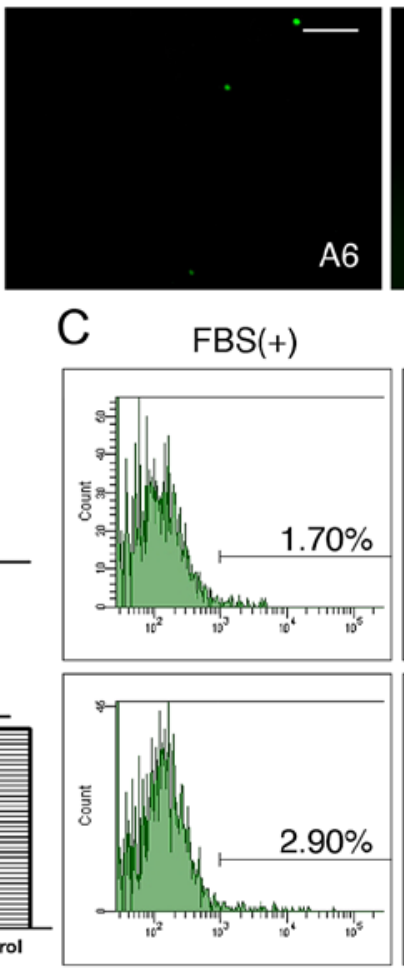

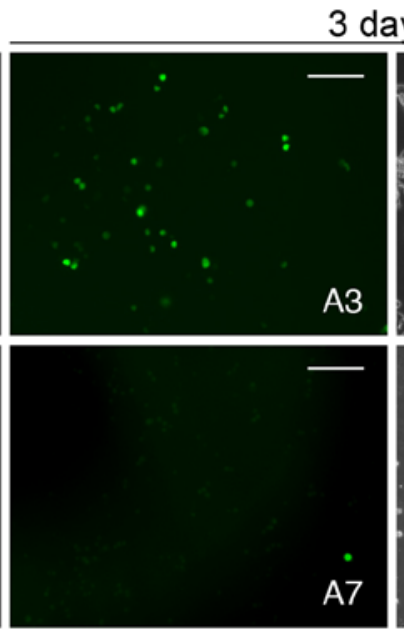

3 days
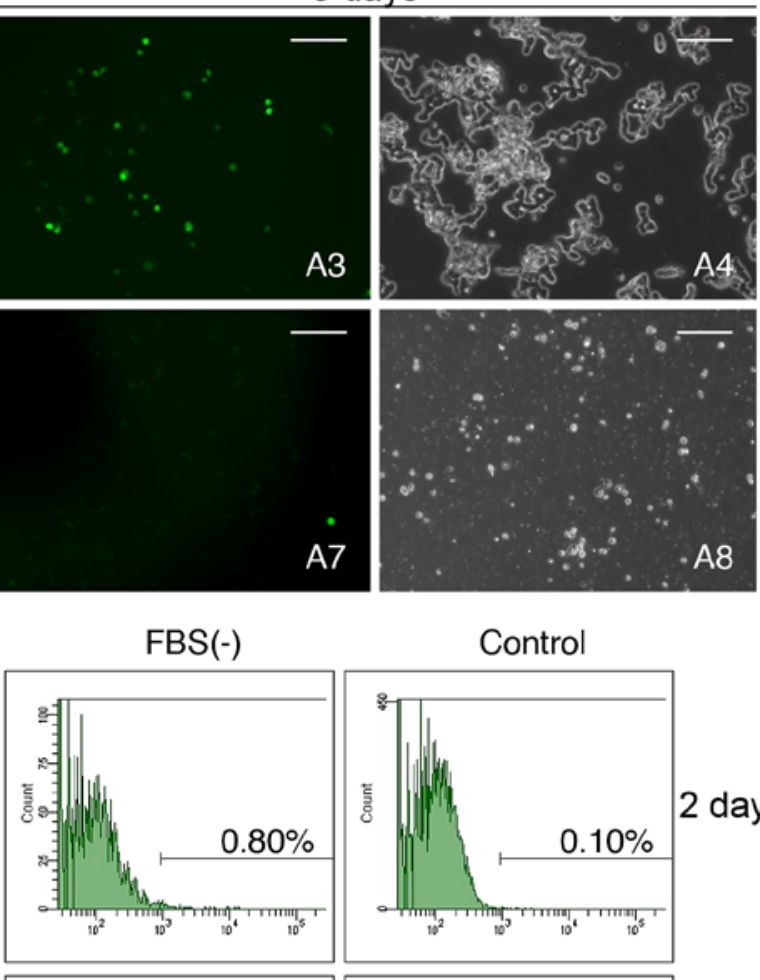

2 days
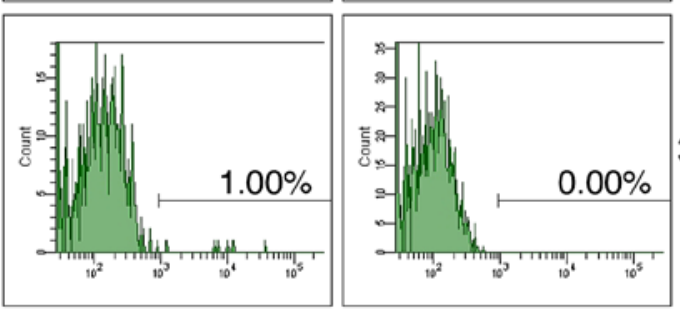

3 days

Figure 6. Comparison of serum-tolerant and serum-free transfection in adherent WERI-Rb1 cells (W-RBCs) by X-treme HP reagent. (A) Immunofluorescence exhibited a progressive increase in green fluorescent protein (GFP) expression in the FBS(+) group (A1-A3), compared with a much lower expression in the FBS(-) group (A5-A7). In addition, cells in serum-free condition exhibited a toxic phenotype (A8) in contrast with the serum-tolerant ones (A4). (B) Statistical analysis of $\mathrm{GFP}^{+}$cells showed a significant increase in the percentage of $\mathrm{GFP}^{+}$cells in the FBS(+) group from day 1 to 3 . (C) FACS indicated that cells expressed GFP in the FBS(+) group from day 2 to 3, compared with the serum-free one and the untransfected control. (D) Cytotoxicity analysis presented a significantly lower survival rate when serum was removed during transfection $\left({ }^{*} \mathrm{P}<0.05,{ }^{* *} \mathrm{P}<0.01\right.$ and $\left.{ }^{* * *} \mathrm{P}<0.001, \mathrm{n}=3\right)$. Scale bars, $100 \mu \mathrm{m}$.

optimize the gene transfection system for retinoblastoma therapy in previous studies. In this study, we systematically investigated three critical elements that contribute to successful gene transfection: the transgene vector, the serum condition, and the cell culture status. We identified an optimized system that would be appropriate for gene transfection of retinoblastoma cells.

Optimization of transgene vectors. Choosing an ideal vector was based on several factors, including the delivery efficiency of therapeutic genes, the avoidance of cytotoxicity, the maintenance of gene expression for an appropriate duration needed to treat the disease, the ability to target specific cells, and a low immune response. Although previous studies adopted some vectors for retinoblastoma gene therapy, these studies mainly focused on transgene effects instead of the vector characteristics, as mentioned above. Therefore, we compared two major factors, the efficacy and the cytotoxicity, of different viral and non-viral vectors, which were confirmed to be feasible for retina gene therapies, to identify appropriate vectors with retinoblastoma tropism.
Most early studies adopted an adenovirus for gene delivery to kill retinoblastoma cells. Nevertheless, adenovirus vectors are immunogenic, and the transgene expression duration is very short. In this study, rAAV vectors were adopted for a number of features that could render them suitable for retinoblastoma gene transfer instead of adenoviruses: i) the ability to transduce both dividing and non-dividing cells; ii) a broad range of serotypes for different retinal cell subset tropism; and iii) low pathogenicity and immunogenicity $(30,31)$. We found that the GFP expression was negative in both the rAAV2 and rAAV2/1 vectors 2 days after transfection. This delayed expression may result from the transcription of rAAV DNA to an active doublestranded form after infecting cells. This phenomenon has also been observed in mouse subretinal rAAV transfection; the target gene showed effective expression 2-3 weeks later (32). Yet, we observed $\mathrm{GFP}^{+}$cells on the 3 rd day by flow cytometry, although the percentage was low $(<1 \%)$. The rAAV2 is the most commonly used serotype in retina gene therapy and is believed to be efficient in photoreceptor transfection $(22,31)$, and rAAV2/1 (containing one rAAV2 capsid) was reported 

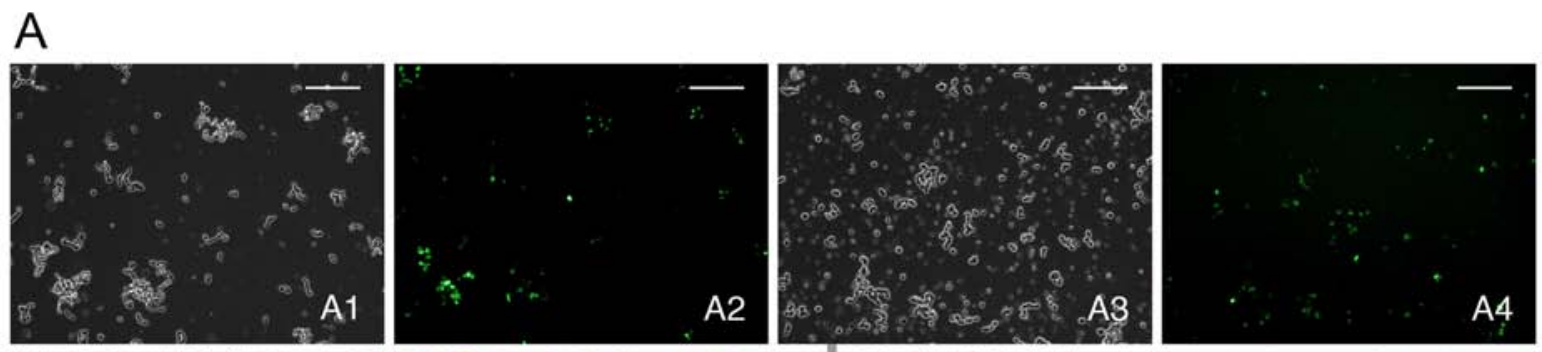

1 day
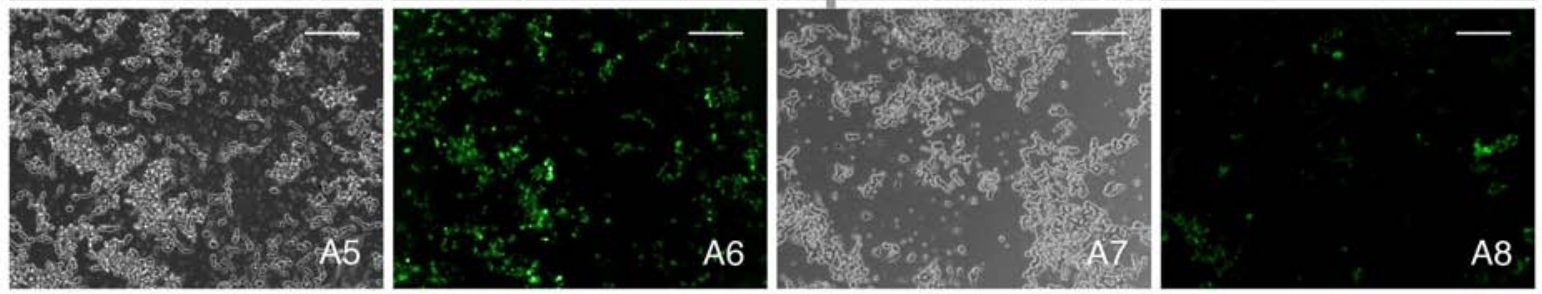

5 days
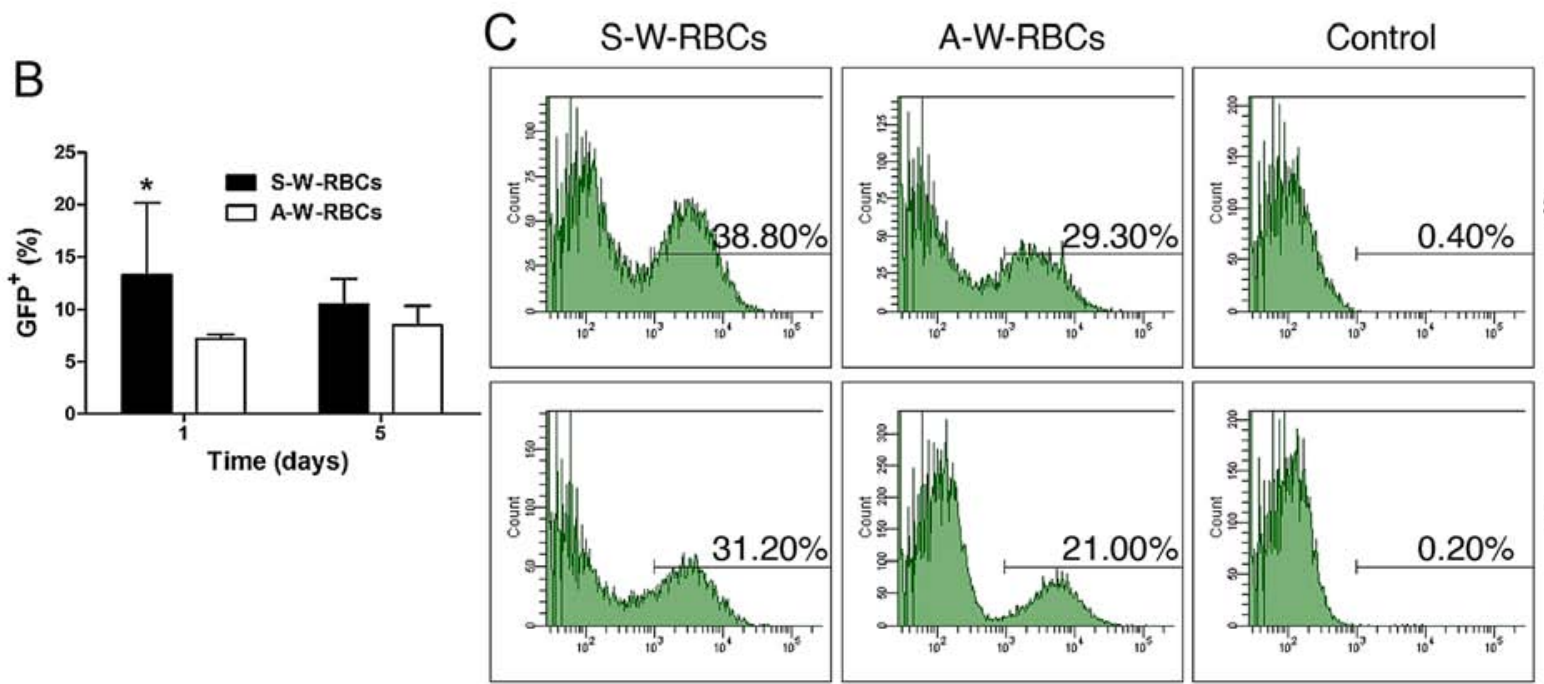

5 days

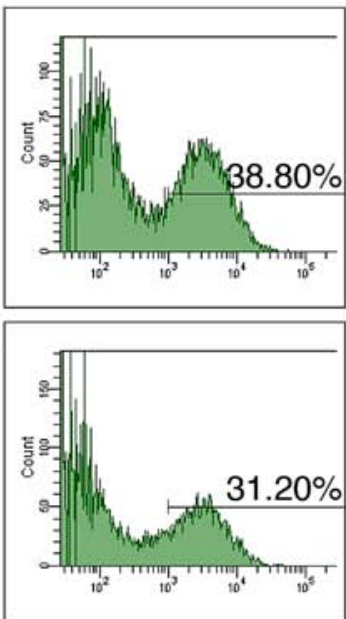

Figure 7. Comparison of suspended and adherent transfection in WERI-Rb1 cells (W-RBCs) by retroviral transfection. (A) Green fluorescent protein (GFP) expression at day 1 and 5 as observed by immunofluorescence. A higher number of S-W-RBCs (A1-A2 and A5-A6) expressed GFP compared with A-W-RBCs (A3-A4 and A7-A8) no matter at the 1st day or at the 5th day. (B) Statistical analysis showed a higher percentage of GFP' cells in S-W-RBCs than in A-WRBCs at day 1 and 5. (C) FACS presented a higher percentage of GFP ${ }^{+}$cells in suspended culture than in adherent culture and untransfected control at both day 5 and $24\left({ }^{*} \mathrm{P}<0.05 ; \mathrm{n}=3\right)$. Scale bars, $200 \mu \mathrm{m}$.

to mainly target RPE (24). Thus, rAAV2 is more likely to be efficient than rAAV2/1 in retinoblastoma transduction given the pre-photoreceptor origin of retinoblastoma (33); however, our results showed that the rAAV2/1 with the lowest MOI $\left(10^{4}\right)$ presented more $\mathrm{GFP}^{+}$cells and living cells than the rAAV2 groups on the 10th day. Hence, rAAV2/1 was considered to be a better vector for W-RBCs as it rendered higher transgene expression with a lower dose and a lower cytotoxicity. This unexpected outcome may be due to the variability of retinoblastoma cells, which differ from normal photoreceptors. Our findings indicated that the rAAV capsid is an essential component for binding the vectors to target cells and for transgene intracellular internalization.

rAAV vectors, however, exhibit a poor transfection ability for W-RBCs, and also suffer from several drawbacks that limit their application for retina gene therapy, including the limited payload capacity (34), the time required for the synthesis of double-stranded DNA (35), the transient transfection due to its non-insertional characteristic (34), and the cytotoxic T-cell (CTL) responses caused by the pre-existing immunity to AAV capsids $(36,37)$. Thus, we tested another potential post-mitotic cell vector, the LV vector, for retinoblastoma gene transfection. LVs are attractive vectors because they can transit much larger DNA than rAAV vectors and can integrate into the host genome to transduce stably (38). They can also avoid CTL responses because LV components have not been pre-exposed in most human subjects (36). LV vectors have previously been shown to be efficient and sustainable in gene transfection of human RPE and photoreceptors $(27,39)$. In this study, the GFP expression following LV transfection was observed 2 days earlier than the $\mathrm{rAAV}$-mediated transfection. A relatively higher transfection efficiency was found in the lower MOI LV group, but there was no significant difference in GFP transfection efficiency between the LV and $\mathrm{rAAV}$ vectors on either day 1 or 5 .

As a classic transgene vector, the retroviral vector was also utilized in this study because of the stable gene integration of the host chromosome and the ability to transfect a wide variety of mammalian cells (40). The data showed that GFP expression was remarkably higher in the retrovirus transfer group compared to both the rAAV and LV groups. This is interesting because rAAV and LV vectors were assumed to be more 

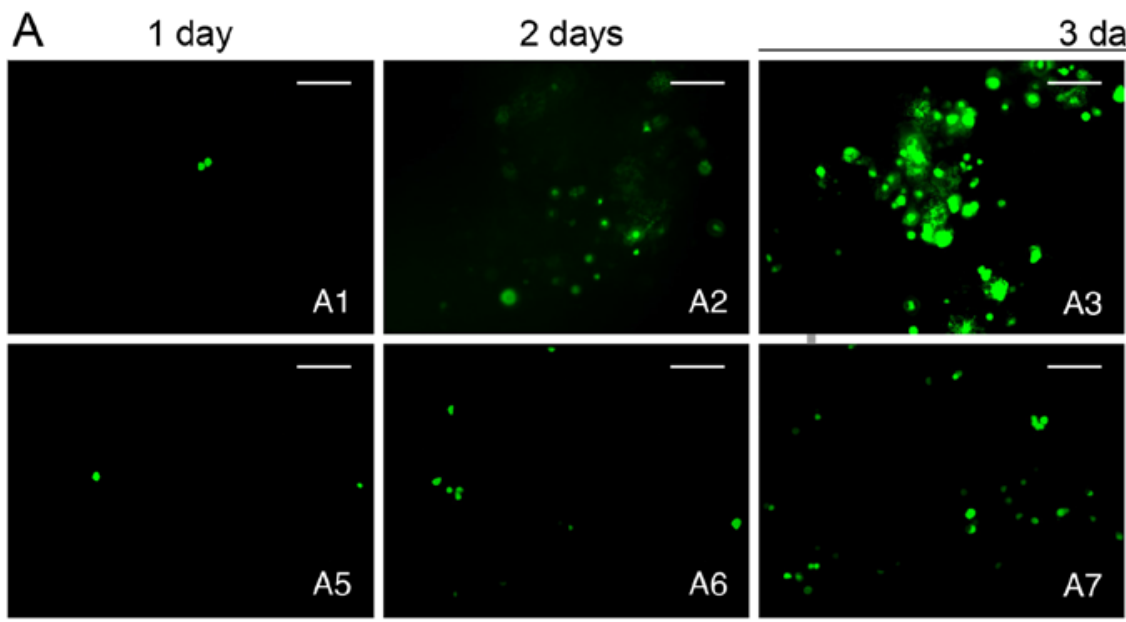

3 days
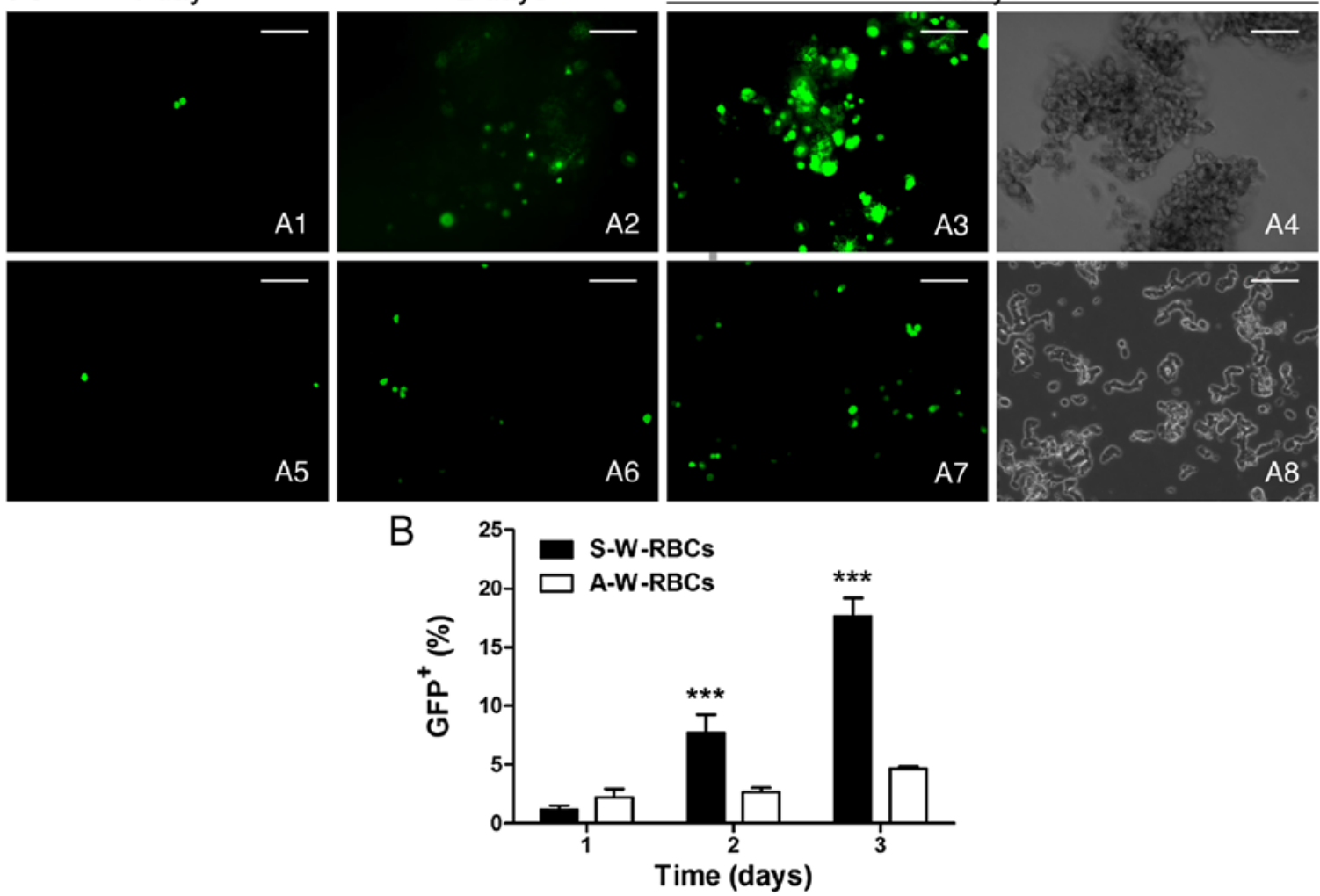

Figure 8. Suspended and adherent transfection comparison of WERI-Rb1 cells (W-RBCs) by X-treme HP reagent. (A) Immunofluorescence showed a progressive increase in green fluorescent protein (GFP) expression in both S-W-RBCs (A1-A3) and A-W-RBCs (A5-A7), and the phenotype of cells in suspended culture (A4) and adherent culture (A8). (B) Statistical analysis presented a markedly higher percentage of GFP ${ }^{+}$cells in the S-W-RBCs than in the A-W-RBCs $\left({ }^{* * * *} \mathrm{P}<0.001, \mathrm{n}=3\right)$. Scale bars, $100 \mu \mathrm{m}$.

efficient in gene transfection than the retroviral vector because the retroviral vector only infects dividing cells, whereas rAAV and $\mathrm{LV}$ vectors are able to infect dividing, post-mitotic, and even terminal differentiated cells. There seems to be three possible reasons. i) The retroviral vector used in this study was pseudotyped with vesicular stomatitis virus $G$ protein (VSV-G), which traffics through different cell compartments instead of normal receptor-mediated mechanisms (39). Thus, the VSV-G pseudotyped retroviral vector could infect almost all species and could facilitate the nuclear entry of transgenes and extend the intracellular half-life of the viral core. ii) WERI-Rb1 is a tumor cell line with a high proliferation rate due to active mitosis; thus, the non-dividing cells only account for a few percentages. This would possibly limit the advantage of the non-dividing cell potential vectors such as rAAVs and LVs. iii) One critical element that contributes to transgene expression is the target cell type. The rAAV vectors perform efficiently in normal photoreceptors, and LV vectors are more active in degenerating photoreceptors. Although retinoblastoma probably originates from pre-photoreceptors, the gene mutations of retinoblastoma make it distinct from normal and degenerative photoreceptors.

Another interesting finding was that there were significantly more $\mathrm{GFP}^{+}$cells following transfecting with the X-treme HP reagent compared with rAAVs and LVs. Non-viral vectors are generally assumed to have a much lower transgene efficiency compared with viral vectors; however, our data showed that the non-viral vector, X-treme HP, efficiently transduced GFP plasmid DNA into W-RBCs similarly to the retroviral vector. Viral vectors are often limited by their cytotoxicity, whereas non-viral vectors are demonstrated to have relatively low cytotoxicity. In this study, the cells in the X-treme HP group exhibited similar survival rates as the untreated W-RBCs and a higher rate than the retroviral-transfected groups, indicating that the X-treme HP reagent has a lower cytotoxicity than its retroviral counterpart. This is con-sistent with previous studies $(41,42)$.

Collectively, the retroviral vectors and X-treme HP were effective for W-RBC gene transfection; however, concerns about the insertional oncogenesis, the risk of replicationcompetent virus (RCV) generation (39), and the inactivation of viral particles by the human complement system (39) must be addressed before clinical utilization of retroviral gene delivery. In addition, the low cytotoxicity and the simple transfection procedure made X-treme HP a more preferable vector for retinoblastoma gene transfection.

Optimization of cell culture system. Although vectors play an important role in gene transfection, unfortunately, there is no vector that can fulfill all ideal vector properties. This has led to the study of other factors, such as a suitable cell culture system for gene delivery. We explored two elements of a cell culture system, which are critical for gene transfection: the cell culture status and the serum in the culture medium.

Retinoblastoma cells are usually suspended when cultured, and gene expression studies are commonly carried out on 
suspended cells; however, rosettes and grape-like cell clusters of retinoblastoma could hinder the attachment of transgenes and the inner cells which are stuck in cell clusters. The adherent culture would facilitate the gene exposure and avoid the chromosomal positional effect of the suspended culture; however, there is no study that has compared the gene expression between suspended and adherent retinoblastoma cells to our knowledge. We compared the GFP expression of suspended W-RBCs with the adherent W-RBCs by both retroviral vector and X-treme HP to identify their efficiency. The data showed that the suspended W-RBCs expressed significantly more GFP protein than the adherent W-RBCs by both the retroviral and the X-treme HP-mediated transfection. Moreover, GFP expression maintained a stable level after a 24-day duration in the suspended cells, unlike the significant decrease in the adherent cells. These data suggest that transgene expression was not similar in the different cell culture statuses and that the suspended status was more favorable for retinoblastoma gene therapy. This may be because the adherent culture is a heterogeneous system in which at least one surface of cells is attached on the plastic plate, which leads to the inefficient attachment of the medium and the whole cells. Hence, it is not capable of sufficient contact between transfection complexes and cells unless the complexes are large enough to settle onto the cells or unless they have high concentrations. In contrast, the suspended cells can be exposed to transfection complexes in a multidimensional manner and can also be easily passaged.

Another vital element affecting of gene transfection is the serum condition. Conventional liposome vectors exhibit an efficient gene transfection ability in serum-free medium (41); however, the serum effect cannot be avoided in future in vivo application. Given the efficiency of GFP transfection in W-RBCs, the X-treme HP was adopted, and its transduction response to serum was explored in this study. The data presented a progressive increase in $\mathrm{GFP}^{+}$cells when 10\% FBS was added into the $\mathrm{X}$-treme HP transfection system in a period of 3 days; however, the $\mathrm{GFP}^{+}$cells were sustained at a significantly lower level when the serum was not added to the system. This phenomenon was observed in both suspended and adherent W-RBCs. These findings indicated that the X-treme HP reagent had an efficient serum-resistant ability despite its lipid component. In addition, the remarkably high number of cells in the trypan blue staining assay and the toxic cell phenotype in the serum-free group revealed that the serum prevented the cells from possible impairment during transfection. Thus, the improvement in cell viability and the previously reported effect of the cell cycle of the serum would further benefit the gene transfection efficiency (43), and this is supported by the fact that there were significantly more $\mathrm{GFP}^{+}$cells in the serumtolerance group than in the serum-free group.

In conclusion, the suspended cell culture was superior to the adherent culture for gene transfection in W-RBCs. Moreover, the serum added to the transfection system did not only protect cell viability but was also conducive for the transduction of the target gene into W-RBCs.

In conclusion, this study provided an effective, convenient, and low cytotoxic system for gene transfection in W-RBCs. To the best of our knowledge, for the first time, we systemically evaluated the influence of gene vectors, cell culture status, and serum conditions on delivering target genes into W-RBCs. This experimental system may be a promising transgene system for the potential gene therapy of retinoblastoma; however, future studies are needed to investigate the transfection system in vivo for further application.

\section{Acknowledgements}

This study was supported by the National Natural Science Foundation of China (grant 81371007,81430009 and 81170846).

\section{References}

1. Bishop JO and Madson EC: Retinoblastoma. Review of the current status. Surv Ophthalmol 19: 342-366, 1975.

2. Shields CL, Meadows AT, Leahey AM and Shields JA: Continuing challenges in the management of retinoblastoma with chemotherapy. Retina 24: 849-862, 2004.

3. Garcia D and Quintyn JC: Treatment of retinoblastoma by radiation therapy. Sixty-six years later. J Fr Ophtalmol 36: 87-88, 2013 (In French).

4. Kleinerman RA, Tucker MA, Abramson DH, Seddon JM, Tarone RE and Fraumeni JF Jr: Risk of soft tissue sarcomas by individual subtype in survivors of hereditary retinoblastoma. J Natl Cancer Inst 99: 24-31, 2007.

5. Mouw KW, Sethi RV, Yeap BY, MacDonald SM, Chen YL, Tarbell NJ, Yock TI, Munzenrider JE, Adams J, Grabowski E, et al: Proton radiation therapy for the treatment of retinoblastoma. Int J Radiat Oncol Biol Phys 90: 863-869, 2014.

6. Chévez-Barrios P, Chintagumpala M, Mieler W, Paysse E, Boniuk M, Kozinetz C, Hurwitz MY and Hurwitz RL: Response of retinoblastoma with vitreous tumor seeding to adenovirusmediated delivery of thymidine kinase followed by ganciclovir. J Clin Oncol 23: 7927-7935, 2005.

7. Hurwitz MY, Marcus KT, Chévez-Barrios P, Louie K, Aguilar-Cordova E and Hurwitz RL: Suicide gene therapy for treatment of retinoblastoma in a murine model. Hum Gene Ther 10: 441-448, 1999.

8. Nichols KE, Walther S, Chao E, Shields C and Ganguly A: Recent advances in retinoblastoma genetic research. Curr Opin Ophthalmol 20: 351-355, 2009.

9. Giacinti C and Giordano A: RB and cell cycle progression. Oncogene 25: 5220-5227, 2006.

10. Jia RB, Zhang P, Zhou YX, Song X, Liu HY, Wang LZ, Luo M, $\mathrm{Lu}$ J, Ge SF and Fan XQ: VEGF-targeted RNA interference suppresses angiogenesis and tumor growth of retinoblastoma. Ophthalmic Res 39: 108-115, 2007.

11. Jia RB, Fan XQ, Wang XL, Zhang XQ, Zhang P and Lu J: Inhibition of VEGF expression by plasmid-based RNA interference in the retinoblastoma cells. Zhonghua Yan Ke Za Zhi 43: 493-498, 2007 (In Chinese).

12. Chau KY and Ono SJ: Gene transfer into retinoblastoma cells. Biotechniques 26: 444-446, 1999.

13. Adachi M, Brooks SE, Stein MR, Franklin BE and Caccavo FA: Destruction of human retinoblastoma after treatment by the E variant of encephalomyocarditis virus. J Neurooncol 77: 233-240, 2006.

14. Di Polo A and Farber DB: Rod photoreceptor-specific gene expression in human retinoblastoma cells. Proc Natl Acad Sci USA 92: 4016-4020, 1995.

15. Herman MM, Perentes E, Katsetos CD, Darcel F, Frankfurter A, Collins VP, Donoso LA, Eng LF, Marangos PJ, Wiechmann AF, et al: Neuroblastic differentiation potential of the human retinoblastoma cell lines Y-79 and WERI-Rb1 maintained in an organ culture system. An immunohistochemical, electron microscopic, and biochemical study. Am J Pathol 134: 115-132, 1989.

16. Muncaster MM, Cohen BL, Phillips RA and Gallie BL: Failure of RB1 to reverse the malignant phenotype of human tumor cell lines. Cancer Res 52: 654-661, 1992.

17. Daya S and Berns KI: Gene therapy using adeno-associated virus vectors. Clin Microbiol Rev 21: 583-593, 2008.

18. Al-Saikhan FI: The gene therapy revolution in ophthalmology. Saudi J Ophthalmol 27: 107-111, 2013.

19. Ali RR, Reichel MB, Thrasher AJ, Levinsky RJ, Kinnon C, Kanuga N, Hunt DM and Bhattacharya SS: Gene transfer into the mouse retina mediated by an adeno-associated viral vector. Hum Mol Genet 5: 591-594, 1996. 
20. Flannery JG,Zolotukhin S, Vaquero MI,LaVail MM, Muzyczka N and Hauswirth WW: Efficient photoreceptor-targeted gene expression in vivo by recombinant adeno-associated virus. Proc Natl Acad Sci USA 94: 6916-6921, 1997.

21. Maguire AM, Simonelli F, Pierce EA, Pugh EN Jr, Mingozzi F, Bennicelli J, Banfi S, Marshall KA, Testa F, Surace EM, et al Safety and efficacy of gene transfer for Leber's congenital amaurosis. N Engl J Med 358: 2240-2248, 2008

22. Maclachlan TK, Lukason M, Collins M, Munger R, Isenberger E, Rogers C, Malatos S, Dufresne E, Morris J, Calcedo R, et al: Preclinical safety evaluation of AAV2-sFLT01- a gene therapy for age-related macular degeneration. Mol Ther 19: 326-334, 2011.

23. Lukason M, DuFresne E, Rubin H, Pechan P, Li Q, Kim I, Kiss S, Flaxel C, Collins M, Miller J, et al: Inhibition of choroidal neovascularization in a nonhuman primate model by intravitreal administration of an AAV2 vector expressing a novel anti-VEGF molecule. Mol Ther 19: 260-265, 2011.

24. Auricchio A, Kobinger G, Anand V, Hildinger M, O'Connor E, Maguire AM, Wilson JM and Bennett J: Exchange of surface proteins impacts on viral vector cellular specificity and transduction characteristics: The retina as a model. Hum Mol Genet 10: 3075-3081, 2001.

25. Pang J, Cheng M, Haire SE, Barker E, Planelles V and Blanks JC: Efficiency of lentiviral transduction during development in normal and rd mice. Mol Vis 12: 756-767, 2006.

26. Mátrai J, Chuah MK and VandenDriessche T: Recent advances in lentiviral vector development and applications. Mol Ther 18: 477-490, 2010

27. Miyoshi H, Takahashi M, Gage FH and Verma IM: Stable and efficient gene transfer into the retina using an HIV-based lentiviral vector. Proc Natl Acad Sci USA 94: 10319-10323, 1997.

28. Garson K, Gamwell LF, Pitre EM and Vanderhyden BC: Technical challenges and limitations of current mouse models of ovarian cancer. J Ovarian Res 5: 39, 2012.

29. Tosetti F, Venè R, Arena G, Morini M, Minghelli S, Noonan DM and Albini A: N-(4-hydroxyphenyl)retinamide inhibits retinoblastoma growth through reactive oxygen species-mediated cell death. Mol Pharmacol 63: 565-573, 2003.

30. Cepko CL: Emerging gene therapies for retinal degenerations. J Neurosci 32: 6415-6420, 2012.

31. Day TP, Byrne LC, Schaffer DV and Flannery JG: Advances in AAV vector development for gene therapy in the retina. Adv Exp Med Biol 801: 687-693, 2014.
32. Janson CG, McPhee SW, Leone P, Freese A and During MJ: Viral-based gene transfer to the mammalian CNS for functional genomic studies. Trends Neurosci 24: 706-712, 2001.

33. Xu XL, Fang Y, Lee TC, Forrest D, Gregory-Evans C, Almeida D, Liu A,Jhanwar SC, Abramson DH and Cobrinik D: Retinoblastoma has properties of a cone precursor tumor and depends upon conespecific MDM2 signaling. Cell 137: 1018-1031, 2009.

34. Koirala A, Conley SM and Naash MI: A review of therapeutic prospects of non-viral gene therapy in the retinal pigment epithelium. Biomaterials 34: 7158-7167, 2013.

35. Boylan NJ, Kim AJ, Suk JS, Adstamongkonkul P, Simons BW, Lai SK, Cooper MJ and Hanes J: Enhancement of airway gene transfer by DNA nanoparticles using a $\mathrm{pH}$-responsive block copolymer of polyethylene glycol and poly-L-lysine. Biomaterials 33: 2361-2371, 2012.

36. McIntosh JH, Cochrane M, Cobbold S, Waldmann $\mathrm{H}$, Nathwani SA, Davidoff AM and Nathwani AC: Successful attenuation of humoral immunity to viral capsid and transgenic protein following AAV-mediated gene transfer with a nondepleting CD4 antibody and cyclosporine. Gene Ther 19: 78-85, 2012.

37. VandenDriessche T: Muscling through AAV immunity. Blood 114: 2009-2010, 2009.

38. Harvey AR, Kamphuis W, Eggers R, Symons NA, Blits B, Niclou $S$, Boer GJ and Verhaagen J: Intravitreal injection of adeno-associated viral vectors results in the transduction of different types of retinal neurons in neonatal and adult rats: A comparison with lentiviral vectors. Mol Cell Neurosci 21: 141-157, 2002.

39. Daly G and Chernajovsky Y: Recent developments in retroviralmediated gene transduction. Mol Ther 2: 423-434, 2000.

40. Liu Y and Deisseroth A: Tumor vascular targeting therapy with viral vectors. Blood 107: 3027-3033, 2006.

41. Ramamoorth $M$ and Narvekar A: Non viral vectors in gene therapy- an overview. J Clin Diagn Res 9: GE01-GE06, 2015.

42. Yin H, Kanasty RL, Eltoukhy AA, Vegas AJ, Dorkin JR and Anderson DG: Non-viral vectors for gene-based therapy. Nat Rev Genet 15: 541-555, 2014

43. Chan CL, Ewert KK, Majzoub RN, Hwu YK, Liang KS, Leal C and Safinya CR: Optimizing cationic and neutral lipids for efficient gene delivery at high serum content. J Gene Med 16: 84-96, 2014. 